Part of Journal of Research of the National Bureau of Standards, Volume 29, September 1942

\title{
SURFACE AVAILABLE TO NITROGEN ON BONE BLACK AND OTHER CARBONACEOUS ADSORBENTS ${ }^{1,2}$
}

\author{
By Victor R. Deitz ${ }^{3}$ and Leland F. Gleysteen ${ }^{3}$
}

\section{ABSTRACT}

The adsorption of nitrogen was determined at liquid nitrogen and liquid oxygen temperatures by measuring the pressure decrease of a known volume of the gas exposed to each of 20 different samples of bone blacks, activated carbons, vegetable carbons, and coconut charcoals. Typical adsorption isotherms of these data are illustrated. Specific surfaces were estimated with fair accuracy from an analysis of the data with the aid of the multimolecular theory of adsorption. The surfaces of new bone chars, service bone chars, and spent bone chars are compared; the ratio of the specific surface of a new char to that of a spent char may be as great as 7 . The distribution of pore sizes in the adsorbents is discussed and the data are divided into five groups, each characterized by a value of $n$, which is defined as the maximum number of adsorbed layers possible on the surface of the material. All the samples in each group have a common isotherm when reduced to unit surface. The differential heats of adsorption are also determined from the data. The adsorption at $77^{\circ} \mathrm{K}$ is also considered from the standpoint of capillary condensation. The volume, as adsorbed liquid nitrogen, is plotted against the corresponding radius of a cylindrical capillary, which is determined from the Kelvin equation.

\section{CONTENTS}

Page

I. Introduction

II. Adsorption experiments

1. Surface area from adsorption measurements ... . . . . . . 193

2. Apparatus

3. Procedure

4. Discussion of adsorption isotherms _....... 197

III. Method of calculating the available surface $\ldots \ldots \ldots 202$

1. Theoretical basis $\ldots \ldots 202$

2. Discussion of table of results

IV. Isotherms reduced to unit surface

V. Heats of adsorption

VI. Dependence of the adsorption on capillarity

VII. References

\section{INTRODUCTION}

The filtration of sugar liquors through bone black has been a part of the procedure for cane-sugar purification for over a century. The technical application of this process has reached a relatively high state

1 This investigation has resulted from a joint Research Project undertaken by the United States Cane Sugar Refiners and the bone char manufacturers and the National Bureau of Standards.

$3 \mathrm{~A}$ part of the material given in this paper was presented before the Division of Sugar Chemistry and Technology of the American Chemical Society at the Memphis meeting, April 1942.

3 Research Associate at the National Bureau of Standards, representing the United States Cane Sugar Refiners and the bone black manufacturers. 
of development without a corresponding advance in knowledge of the fundamental scientific principles involved. This situation is clearly reflected in the abundance of the patent literature on bone char as compared with purely scientific contributions. In realization of these conditions a joint research project has been undertaken by the United States Cane Sugar Refiners, the bone-black manufacturers, and the National Bureau of Standards. The object of this investigation is to study the fundamental physical and chemical principles which lead to the decolorization and purification of sugar liquors by bone char and analogous materials.

A vast scientific literature has accumulated on the general subject of carbonaceous and noncarbonaceous adsorbents. This includes investigations of their nature, preparation, and activation, of their use in gas adsorption and adsorption in liquids, and upon their use as catalysts. There are numerous applications of carbons to a variety of processes, such as the purification of sugar, foods, and medicines; the treatment of water and sewage; and refining of petroleum products; the recovery of solvents and gases; and, of timely interest, for protection against toxic gases. There will be no attempt in this report to cover the available literature. Reference is made, however, to the extensive bibliography which has been prepared in connection with this project for the period 1900-41, inclusive, on the general subject of adsorption from the gas phase and from solution, which is expected to be available in printed form at an early date.

One characteristic of all activated carbons and similar adsorbents is the large specific surface area which is attributed to them from many kinds of data. Estimates range from a thousand to a million times that of the external geometrical area as determined microscopically. This would include the surface bounding the cracks, pores, crevices, and channels, or whatever be the particular disposition of the interstices of the adsorbent. The chemist is, of course, interested in all regions to which a gas or solution may have access and hence be available for possible surface reaction. Consequently the primary problem is to obtain a fairly accurate measure of the total surface of the adsorbents with the object of studying the availability of this surface to gas molecules having various chemical and physical properties, and second, to study that part of the surface accessible to solution phenomena.

Many methods have been proposed to measure surface areas. Among these may be mentioned first the direct observation of the shape and dimensions of particles with a microscope, a method of obviously limited scope in adsorbents with large internal surfaces. The adsorption of radioactive indicators and the adsorption of dyes have been widely used since being introduced by Paneth [1]. ${ }^{4}$ Other methods that may be mentioned are the rate of chemical attack, which has been employed by comparison with a similar material of known surface area; the polarization during electrolysis on metal surfaces, which involves the use of the hydrogen ion in determining the extent of surface; the interference colors produced on metal surfaces, and the heat of wetting have also found application. The permeability method, which is concerned with the rate of flow of a fluid through a bed of material, has been applied by Carman [2] to evaluate the sur-

- Figures in brackets indicate the literature references at the end of this paper. 
face areas of powders. Recently Kistler [3] has used the heat conductivity of a porous substance to estimate surface area.

Objections can be raised to any of the above methods on grounds of either their inapplicability to the present materials or their inadequate fundamental interpretation. There is described in this paper a method which seems to be less open to criticism, namely the measurement of the adsorption isotherm at low temperatures. Such data were obtained for 20 different materials at both liquid oxygen and liquid nitrogen temperatures, and the surface areas were calculated from these data.

\section{ADSORPTION EXPERIMENTS}

\section{SURFACE AREA FROM ADSORPTION MEASUREMENTS}

The extent to which a solid is exposed to the action" of "a gas or liquid is generally much greater than the visible apparent surface. Obviously a large part of a porous structure is permeated only by small gas molecules, and it is such minute units that must serve as a measuring standard if the total surface is to be measured. Since molecular species vary in size and other properties, this qualification must be placed in the definition of the surface so measured. For example, the present investigation is a measurement of the surface available to nitrogen molecules.

When a gas or vapor is admitted to a thoroughly evacuated adsorbent, the molecules of the former distribute themselves between the gas phase and the adsorbed phase. The particular adsorption phenomenon in the neighborhood of the saturation point of the gas, generally termed van der Waals' adsorption, is usually identified with weak forces of interaction between the solid and the gas, similar to forces active in condensation phenomena. The characteristics of this type of adsorption are (1) the rapid attainment of an equilibrium state, and (2) the nonspecific nature of the adsorption. In contrast to this type is the so-called chemisorption in which the forces of interaction are strong, specific, and exhibit a similarity to the forces active in chemical reactions. Van der Waals' adsorption is free of chemisorptive effects except insofar as local regions modify the early stages in the formation of the first adsorbed layer.

The technique of measuring adsorption isotherms at low temperatures has been recently applied by Emmett and Brunauer [4] in determining the surface area of iron catalysts for synthetic ammonia. In a later paper by Brunauer and Emmett [5] the same method was used to determine the surface areas of a variety of adsorbents, including two charcoal samples. Finally Brunauer, Emmett, and Teller [6] derived isotherm equations for multimolecular adsorption which have proved to be of some generality. The application of this theory to bone char and to other adsorbents containing carbon is discussed in section IV of this paper, in connection with the measurement of nitrogen isotherms.

While the present paper was in preparation, three applications of this method have been published for a number of finely divided pigments and carbon blacks. It has been shown from electron-microscope pictures that carbon-black particles are approximately spherical, and an average value for the diameter is so obtained. This has been compared by Emmett and De Witt [7] with their value obtained from 


\section{Journal of Research of the National Bureau of Standards}

a determination of the surface area by adsorption of nitrogen at $77^{\circ} \mathrm{K}$. Excellent agreement was obtained: the particular carbon-black particles yielded a value of $280 \mathrm{~A}$ from electron-microscope data as compared with 310 A obtained from the nitrogen adsorption. Even more striking confirmation was found by Smith, Thornhill, and Bray [8], who compared the results for two samples of carbon black. Their acetylene-black sample showed a surface of $64 \mathrm{~m}^{2} / \mathrm{g}$ by adsorption of nitrogen, or an average particle diameter of $533 \mathrm{~A}$; the electron microscope value was $510 \mathrm{~A}$. Another sample of standard-grade rubber black (their number 6) showed a surface of $114 \mathrm{~m}^{2} / \mathrm{g}$ corresponding to a particle diameter of $284 \mathrm{~A}$; the electron microscope value was $280 \mathrm{~A}$. P. H. Emmett [14] recorded still another case for acetylene-black particles, the diameter of which was $520 \mathrm{~A}$ as determined from adsorption of nitrogen and $510 \mathrm{~A}$ as obtained with the electron microscope.

\section{APPARATUS}

The experiments to be described involve simply a determination of the pressure of nitrogen in a known volume over the adsorbent in the range of 1 to $760 \mathrm{~mm}$ of mercury after the introduction of a known quantity of the gas. The outline of the apparatus is shown in figure 1. With the exception of the pumps, gages, and other accessories, the apparatus consists of two sections: (1) the gas burette, manometer, and connecting capillary tubing up to stopcocks 2 and 3 ; and (2) the adsorption cell and the capillary tubing up to stopcocks 1 and 3 , including the bore of stopcock 3 . The gas burette, surrounded by a water jacket, was calibrated before assembling the apparatus by finding the weight of mercury required to fill each bulb. The mercury column in the manometer is about $1 \mathrm{~cm}$ in diameter. Behind the manometer is a mirrored meter scale, and the position of the mercury meniscus is noted when it is in coincidence with its image. The important stopcocks have hollow-stopper plugs with oblique bore, and were specially ground. The inside diameter of the capillary tubing was about $1 \mathrm{~mm}$.

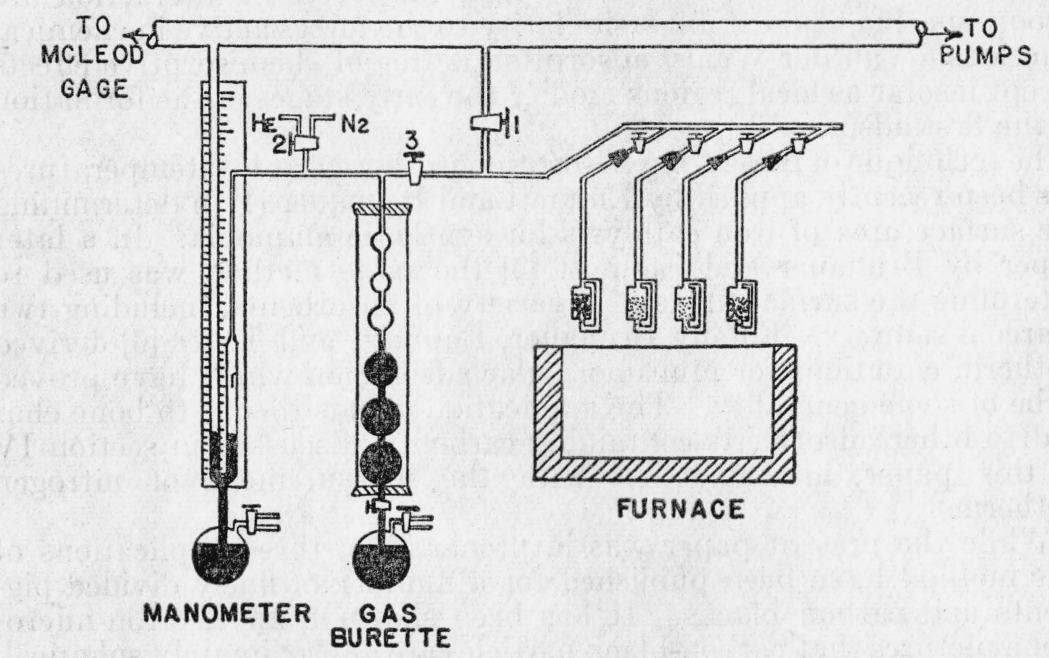

FIGURE 1.-Adsorption apparatus for gases. 
The tube which contains the sample of adsorbent is shown in figure 2. Attention is directed to three features of construction: (1) The adsorbent is evacuated from above and from beneath, which, coupled with slow initial evacuation, is necessary to keep the sample in place; (2) the adsorbent sample, when placed beneath the surface of the cooling liquid, is really at the temperature of the liquid, since there is no opportunity for heat conduction through the connecting tubing to the sample; (3) the additional U-bend protects the adsorbent from stopcock grease and mercury vapor during the determination. After a known weight of sample is introduced through the side arm, it is sealed and the tube is attached to the main apparatus through a small ground-glass joint with a plastic cement.

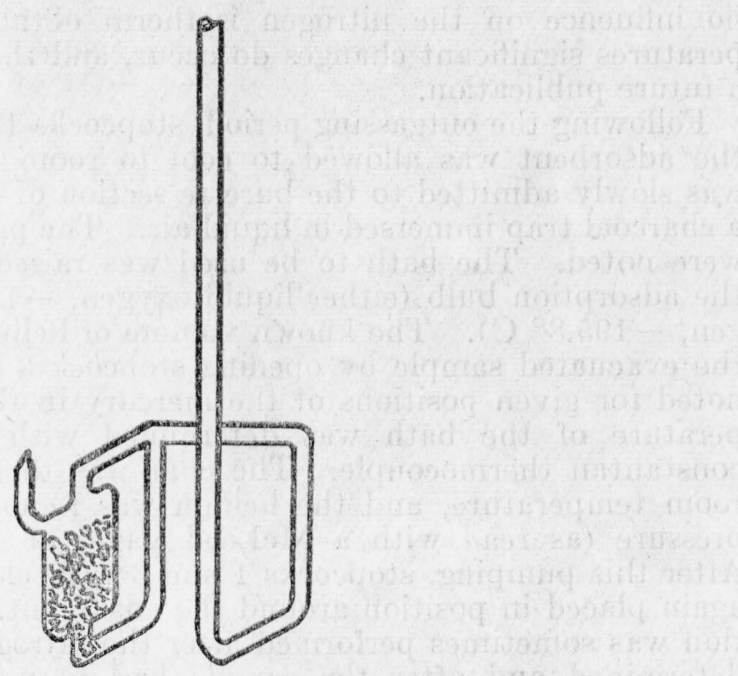

Figure 2.-Special tube for the adsorbent in the adsorption of gases.

With the use of the manifold system shown in figure 1 , it is possible to run four different samples in sequence. The space around the sample of adsorbent and in the connecting capillary tubing is termed the "dead-space" of the apparatus. Its volume must of course be known in order to calculate the volume of gaseous nitrogen over the adsorbent at each pressure. This has been done under the same conditions as in the adsorption experiments by calibration with a known volume of purified helium. Helium is not appreciably adsorbed at the temperatures employed, and it is readily removed by pumping, with the adsorbent kept at room temperature.

\section{PROCEDURE}

The weight of the sample of adsorbent varied between 0.25 and 1.0 g. Except for samples 19 and 20, which are powdered materials, the particle sizes were between 35 and 80 mesh. The preparation of these samples and the analysis for carbon and hydrogen have been described [10]. 
The samples of adsorbents contained in weighing tubes were dried in an air oven at $130^{\circ} \mathrm{C}$ for about 20 hours and were cooled in a desiccator. The weight was determined before and after the delivery of the sample into the adsorption tube, the transfer being accomplished as rapidly as possible. ${ }^{5}$

The four samples were simultaneously evacuated and heated according to a prescribed procedure. A mercury-diffusion pump supported by a Hyvac pump maintained a pressure of about $10^{-5} \mathrm{~mm}$ for periods of evacuation which lasted 18 to 24 hours. The temperature of outgassing could be varied up to $900^{\circ} \mathrm{C}$, but in the experiments reported in this paper the temperature was between $300^{\circ}$ and $400^{\circ} \mathrm{C}$ for all the materials. The continued outgassing of the samples between $300^{\circ}$ and $400^{\circ} \mathrm{C}$ for periods longer than 18 to 24 hours had no influence on the nitrogen isotherm obtained. At higher temperatures significant changes do occur, and these will be reported in a future publication.

Following the outgassing period, stopcocks 1 and 3 were closed and the adsorbent was allowed to cool to room temperature. Helium was slowly admitted to the burette section of the apparatus through a charcoal trap immersed in liquid air. The pressure and the volume were noted. The bath to be used was raised into position around the adsorption bulb (either liquid oxygen, $-183^{\circ} \mathrm{C}$; or liquid nitrogen, $-195.8^{\circ} \mathrm{C}$ ). The known volume of helium was expanded onto the evacuated sample by opening stopcock 3 and the pressure then noted for given positions of the mercury in the burette. The temperature of the bath was determined with a calibrated copperconstantan thermocouple. The char was then allowed to warm to room temperature, and the helium was removed by pumping to a pressure (as read with a McLeod gage) of $10^{-5} \mathrm{~mm}$ of mercury. After this pumping, stopcocks 1 and 3 were closed and the bath was again placed in position around the adsorbent. The helium calibration was sometimes performed after the nitrogen isotherm had been determined and after the sample had been outgassed for several hours. The results were exactly the same, which indicates that the removal of helium by pumping at room temperature is essentially complete as far as this type of measurement is concerned.

Purified nitrogen was introduced into the first section with stopcock 3 closed. After the pressure was measured for a given setting of the level of mercury in the burette, the nitrogen was introduced into the evacuated sample. For values less than about 0.6 of the relative pressure, which is defined as the ratio of the pressure of the gas to the saturation pressure, a steady state was obtained in 15 to 20 minutes; at higher relative pressures a period of as much as an hour was sometimes necessary. Both adsorption and desorption points were obtained in order to detect possible hysteresis.

Liquid oxygen or liquid nitrogen was prepared from tank oxygen or tank nitrogen by passing the gas under pressure through a copper coil immersed in liquid air. The temperature of the liquid air determines the pressure necessary for liquefaction. This apparatus

- The weight of adsorbent need be known only to about 0.5 percent. Consequently the relatively elaborate method of drying discussed in [10] is not required. 
has been described by Lane and Watson [9]. During the adsorption experiments, the bath was maintained at a constant level by additions from a reservoir of liquid nitrogen or liquid oxygen.

The nitrogen for the adsorption measurements was the commercial water-pumped product, which was purified by passage through a tube packed with metallic copper maintained at about $450^{\circ} \mathrm{C}$. The gas then passed in order through Ascarite, activated alumina, and phosphorus pentoxide. It was drawn into the adsorption burette as required, and the excess was allowed to bubble through a mercury trap into the atmosphere.

\section{DISCUSSION OF ADSORPTION ISOTHERMS}

Isotherms for 20 different samples are reported. These include four samples of new, that is unused, bone char from different sources;

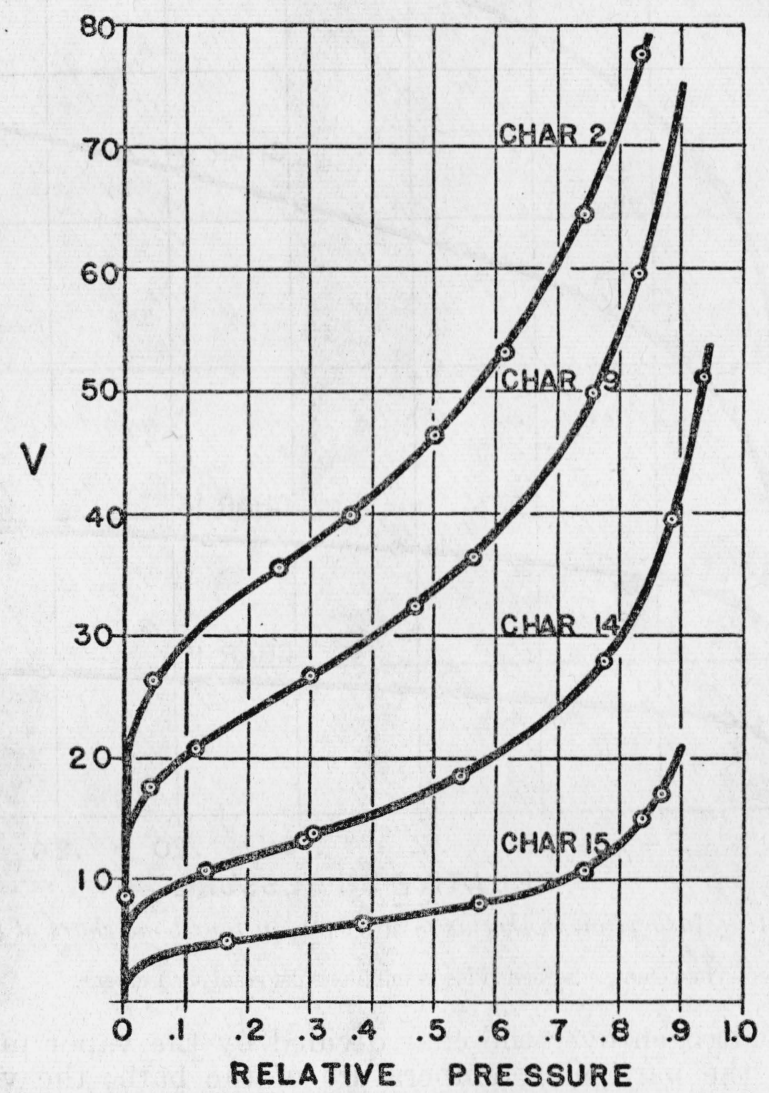

FIGURE 3.-Adsorption isotherms of nitrogen on four bone chars at $7^{\circ}{ }^{\circ} \mathrm{K}$.

The volume adsorbed, $V$, is in milliliters per gram of adsorbent.

six bone chars obtained from several cane-sugar refineries, where they were sampled at various stages in the char filtration; six decolorizing carbons other than bone char; two activated coconut-shell charcoals; 
and, in order to broaden the scope of materials investigated, a sample of carbon black used in rubber compounding and a sample of petroleum coke. As mentioned before, these samples are the identical materials, and are numbered the same, as those previously described [10].

Altogether 57 nitrogen isotherms are considered in this paper for these 20 samples. Figures $3,4,5,6,7$, and 8 are typical. Figure 3 illustrates the isotherms for four bone chars at $77^{\circ} \mathrm{K}$. The coordinates are: relative pressure, $x$, as abscissa, $x$ being equal to the

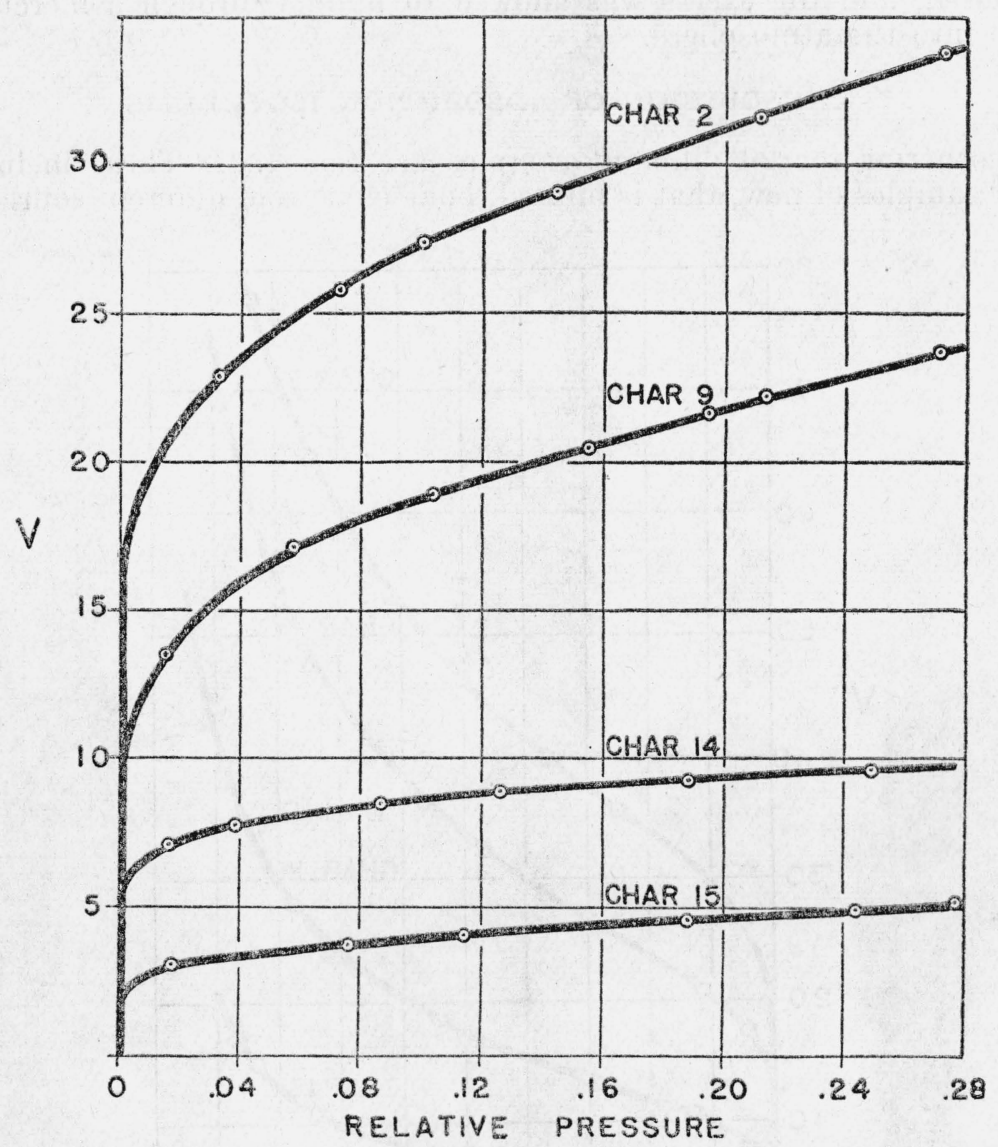

FigURE 4.-Adsorption isotherms of nitrogen on four bone chars at $90^{\circ} \mathrm{K}$.

The volume adsorbed, $V$, is in milliliters per gram of adsorbent.

pressure of nitrogen over the char divided by the vapor pressure of nitrogen at the particular temperature of the bath; the volume of nitrogen absorbed per gram, $V$, as ordinate, where the volume has been calculated to the standard conditions of $0^{\circ} \mathrm{C}$ and $760-\mathrm{mm}$ pressure. The curve, char 2, is for a new sample of bone char; the two next curves, chars 9 and 14, are for service chars, of which char 9 had been in use for the shorter time; the bottom curve, char 15, is for a spent bone char. 


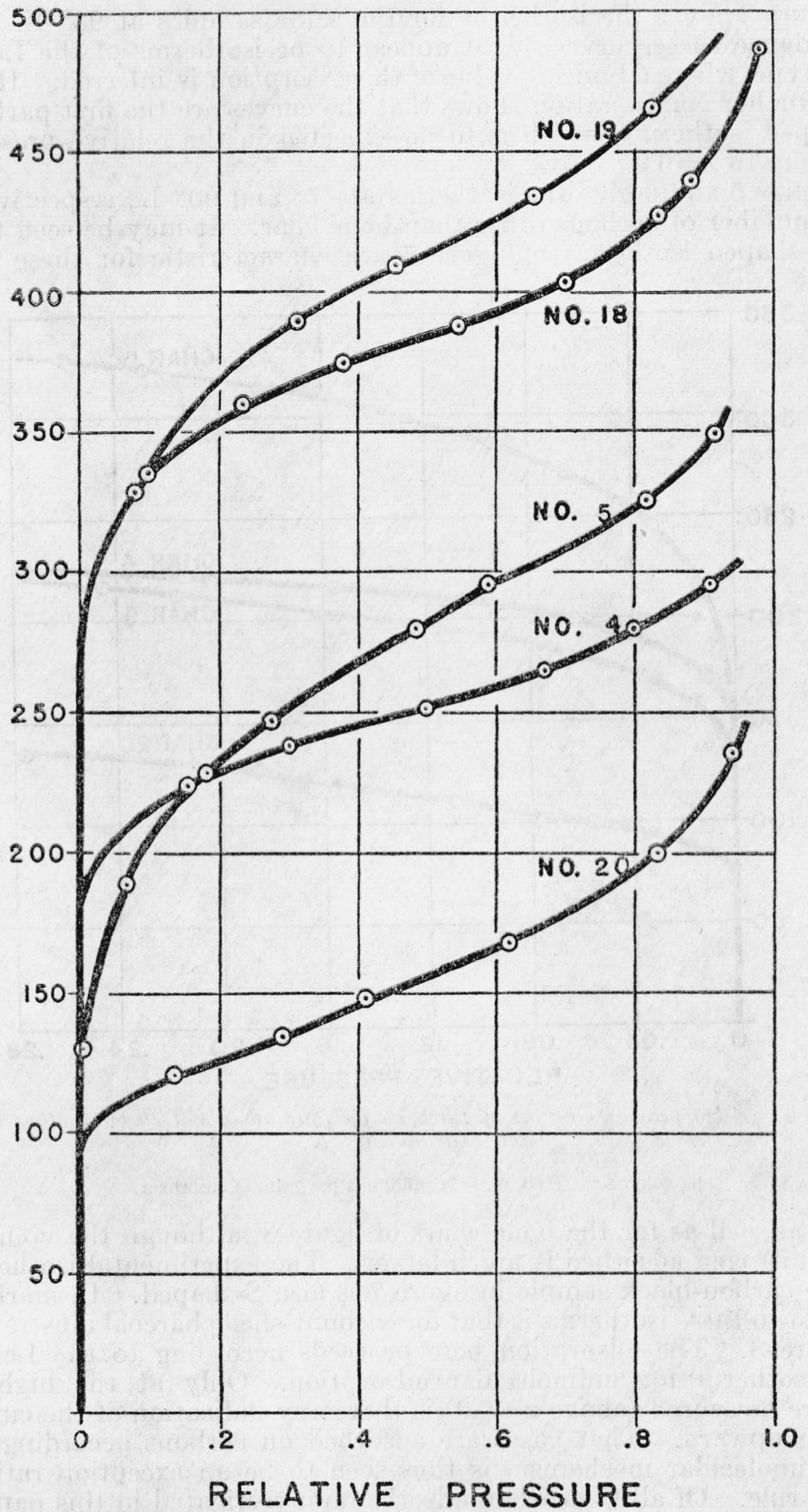

FIGURE 5.-Adsorption isotherms of nitrogen on five adsorbent carbons other than bone char at $77^{\circ} \mathrm{K}$.

The volume adsorbed, $V$, is in milliliters per gram of adsorbent. 
Figure 4 gives the isotherms for the same samples at $90^{\circ} \mathrm{K}$. At first glance these curves might appear to be isotherms of the Langmuir type, where a limiting value of the adsorption is inferred. However further consideration shows that the curves are the first parts of $\mathrm{S}$-shaped isotherms, which is to be expected in the relative pressure range up to $x=0.3$.

Figures 5 and 6 give the isotherms at $77^{\circ}$ and $90^{\circ} \mathrm{K}$, respectively, for a number of carbons other than bone char. It may be seen that the S-shaped isotherms of figure 5 are characteristic for these ma-

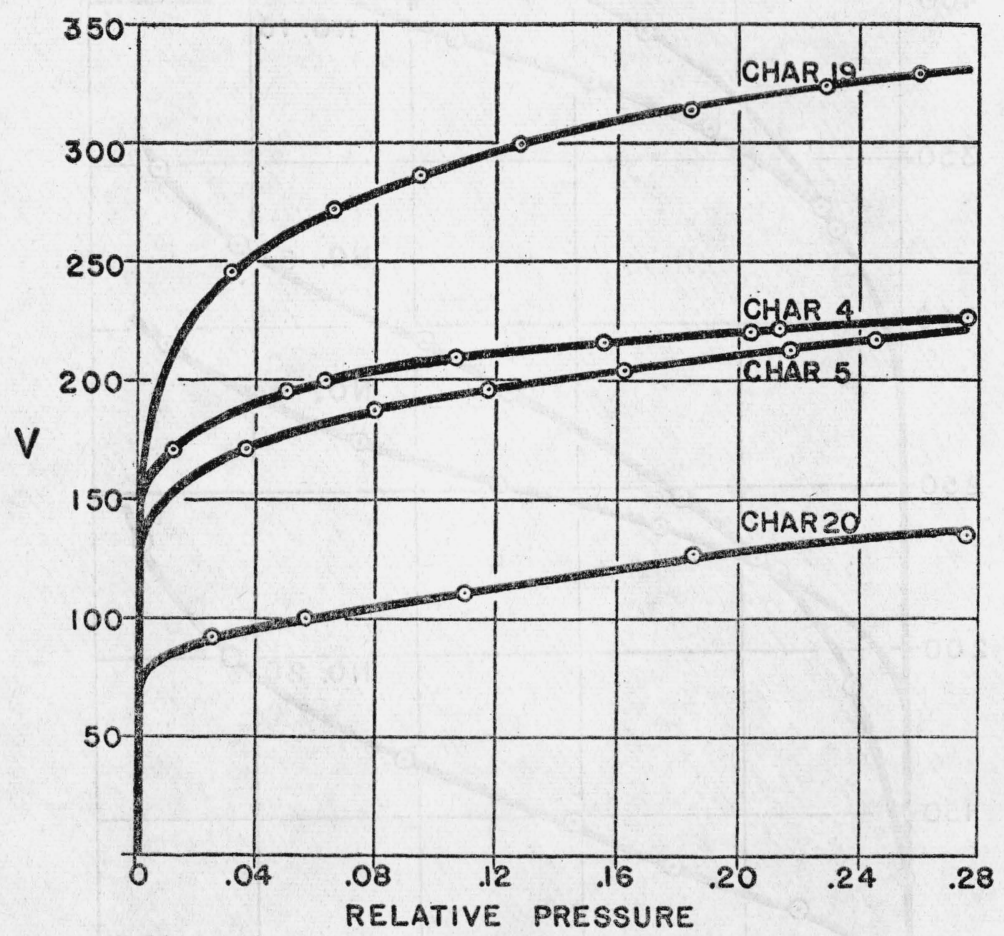

FIgURE 6.-Adsorption isotherms of nitrogen on four adsorbent carbons other than bone char at $90^{\circ} \mathrm{K}$.

The volume adsorbed, $V$, is in milliliters per gram of adsorbent.

terials as well as for the bone chars of figure 3, although the volume of the nitrogen adsorbed is much larger. The experimental isotherm for the carbon-black sample in figure 7 is also S-shaped. In marked contrast to these isotherms is that for coconut-shell charcoal illustrated in figure 8. The adsorption here proceeds according to the Langmuir isotherm for unimolecular adsorption. Only at the highest pressure measured (above $x=0.9$ ) is there any indication of the curve turning upward. That gases are adsorbed on carbons according to the unimolecular mechanism is thus seen to be an exception rather than a rule. Of all the carbon adsorbents investigated in this paper, coconut-shell charcoal alone shows this property. 
It is important to note that no pronounced hysteresis was detected in these experiments. Upon several occasions desorption points taken directly after the greatest pressure reading of the experiment were in complete agreement with the adsorption points.

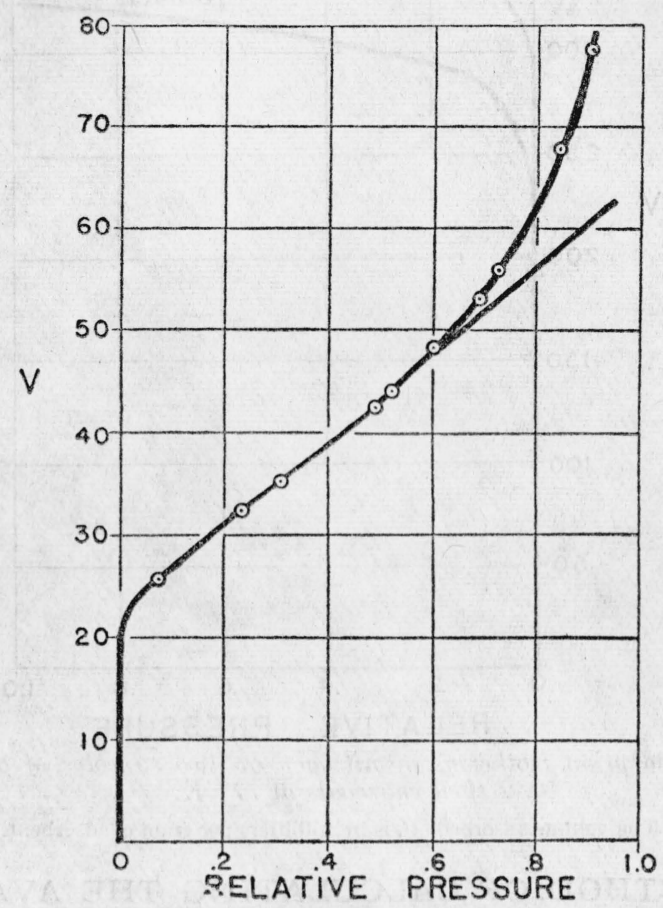

Figure 7.-Observed and calculated isotherms of nitrogen on Arrow carbon black at $77^{\circ} K$.

Experimental points are in circles, and the curve is calculated with $n=4$. The volume absorbed, $V$, is in milliliters per gram of absorbent. It is to be noted that as saturation is approached, $n$ most probably increases.

It may be seen that the isotherms at $90^{\circ} \mathrm{K}$ (figs. 4 and 6 ) extend about one-third toward saturation pressure and, therefore, are to be compared with the first third of the curves at $77^{\circ} \mathrm{K}$ (figs. 3 and 5). The curves in figure 6 also appear to be of the Langmuir type, but are merely the first portions of the S-shaped curves. Readings in the neighborhood of saturation are difficult because of the sensitivity of adsorption to small changes in pressure and temperature and the danger of condensation as the gas at a higher pressure is introduced to the adsorbent. It is to be further noted that the adsorption of carbon 19, which has an S-shaped curve, is greater in general than that of the coconut-shell charcoal 1, which is shown to follow a unimolecular isotherm, although, as will be shown later, the surface is greater for the coconut charcoal. 


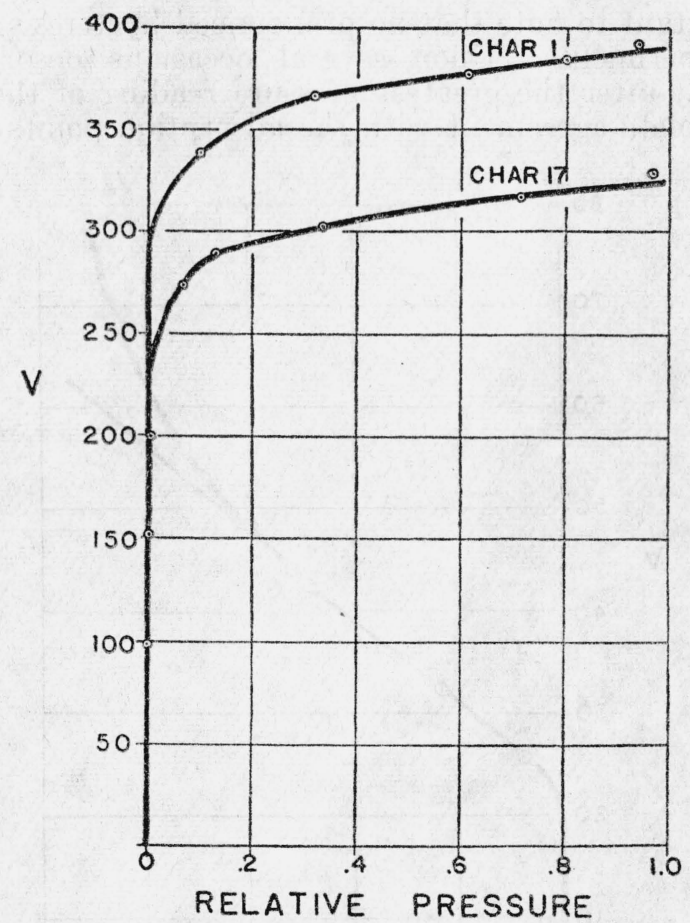

Figure 8.-Adsorption isotherms of nitrogen on two samples of activated coconutshell charcoals at $\% 7^{\circ} K$.

The volume adsorbed, $V$, is in milliliters per gram of adsorbent.

\section{METHOD OF CALCULATING THE AVAILABLE SURFACE}

\section{THEORETICAL BASIS}

Brunauer, Emmett, and Teller [6] have developed a theory to account for the adsorption of gases in multimolecular layers. The development is a generalization of Langmuir's treatment of the unimolecular layer [11], and the theory is quantitative with certain limitations. According to these authors a statistical equilibrium exists between the formation of various layers due to condensation of the gas and the removal of the layers due to evaporation. By equating the rate of condensation of gas molecules on top of the $i$ th layer to the rate of evaporation from the $(i+1)$ th layer, an expression is derived which can be summed over the entire surface. The principal assumptions of this theory may be listed as follows: (1) the postulates of Langmuir as to the expressions for the rates of adsorption and evaporation; (2) the heat of adsorption in a given layer is independent of the number of adsorbed molecules already present; (3) the heats of adsorption in the second, third, and higher layers are equal to each other and to the heat of liquefaction $\left(E_{L}\right) ;(4)$ the ratio of the rate constant for evaporation to the rate constant for condensation is the 
same in the second and higher layers; (5) the heat of adsorption in the first layer, $E_{1}$, may be estimated if the ratio of the rate constants in the first layer is assumed to be the same as in higher layers. These assumptions limit the pressure range to which the theory can be applied. It may not be applicable to relative pressures less than about 0.05 , since local enhanced heats of adsorption may lead to chemisorptive processes. Also at the higher relative pressures approaching saturation, the interactions of neighboring molecules within the layer become significant and may lead to deviations.

Three equations are developed in [6] which have application to the data of this paper:

$$
\begin{aligned}
& V=\frac{v_{m} c x}{1-x}\left[\frac{1-(n+1) x^{n}+n x^{n+1}}{1+(c-1) x-c x^{n+1}}\right] \\
& V=\frac{v_{m} c x}{1+c x} \quad \text { or } \quad \frac{p}{V}=\frac{p_{0}}{c v_{m}}+\frac{p}{v_{m}} \\
& V=\frac{v_{m} c x}{1-x}\left[\frac{1}{1-x+c x}\right] \quad \text { or } \quad \frac{p}{V\left(p_{0}-p\right)}=\frac{1}{v_{m} c}+\left[\frac{c-1}{v_{m} c}\right] \frac{p}{p_{0}}
\end{aligned}
$$

$V=$ the volume of gas at $0^{\circ}$ and $760 \mathrm{~mm}$ adsorbed per gram.

$v_{m}=$ the volume of gas at $0^{\circ}$ and $760 \mathrm{~mm}$ which, when adsorbed, covers the surface of $1 \mathrm{~g}$ of the adsorbent with a unimolecular layer.

$p=$ the pressure.

$x=$ the relative pressure of the gas and is equal to $p / p_{0}$, where $p_{0}$ is the saturation pressure of the gas at the temperature of the adsorption.

$n=$ the maximum number of adsorbed layers to which the adsorption is limited in thickness.

$c=$ the measure of the increase of the heat of adsorption over the heat of liquefaction $\left(E_{L}\right)$, namely, $E_{1}-E_{L}=2.303 R T \log c$, where $E_{1}$ is the heat of adsorption in the first layer, $R$ is the gas constant in calories per mole per degree, and $T$ is the temperature in degrees $\mathrm{K}$. Equation 1 was derived by summing the condensation-evaporation equilibria over the total surface with the provision that $n$ is finite. This factor, $n$, will be referred to in some detail in this paper.

Equations 2 and 3 are limiting cases of eq 1 . When $n=1$, eq 1 reduces to the Langmuir-type eq 2 , which accounts very well for the data obtained with the activated coconut-shell charcoals. From the second formulation of eq 2 a straight-line graph may be obtained by plotting $p / V$ against $p$, and the values of $v_{m}$ and $c$ may be calculated from the slope and intercept, respectively. Figure 9 illustrates the behavior of a sample of coconut-shell charcoal. The agreement with the required linearity is excellent.

In contrast to unimolecular adsorption, there is the opposite extreme of adsorption on open free surfaces where $n$ may be infinitely large, that is, where there is no limitation to the number of adsorbed layers that can form on the surface. In this case eq 1 reduces to eq 3 . For values of $n$ as large as 4 or 5 , which is the case for bone chars, and for values of $x$ up to 0.25 , eq 3 becomes a good approximation to eq 1 . Hence to use this approximation, one plots the experimental isotherm in the low-pressure region with $p / V\left(p_{0}-p\right)$ as ordinate and $x$ as 
abscissa, according to the second formulation of eq 3 , and from the intercept of the straight line, equal to $1 / v_{m} c$, and its slope, equal to $(c-1) / v_{m} c$, it is possible to evaluate $c$ and $v_{m}$. In applying these equations to the bone-char data, such linear curves are obtained, as may be seen in figure 10 . The data used are the same as those given in the isotherms of figure 4.

There is an alternative method of evaluating $v_{m}$ and $c$, which may be used for bone chars and which must be used in the case of decoloriz-

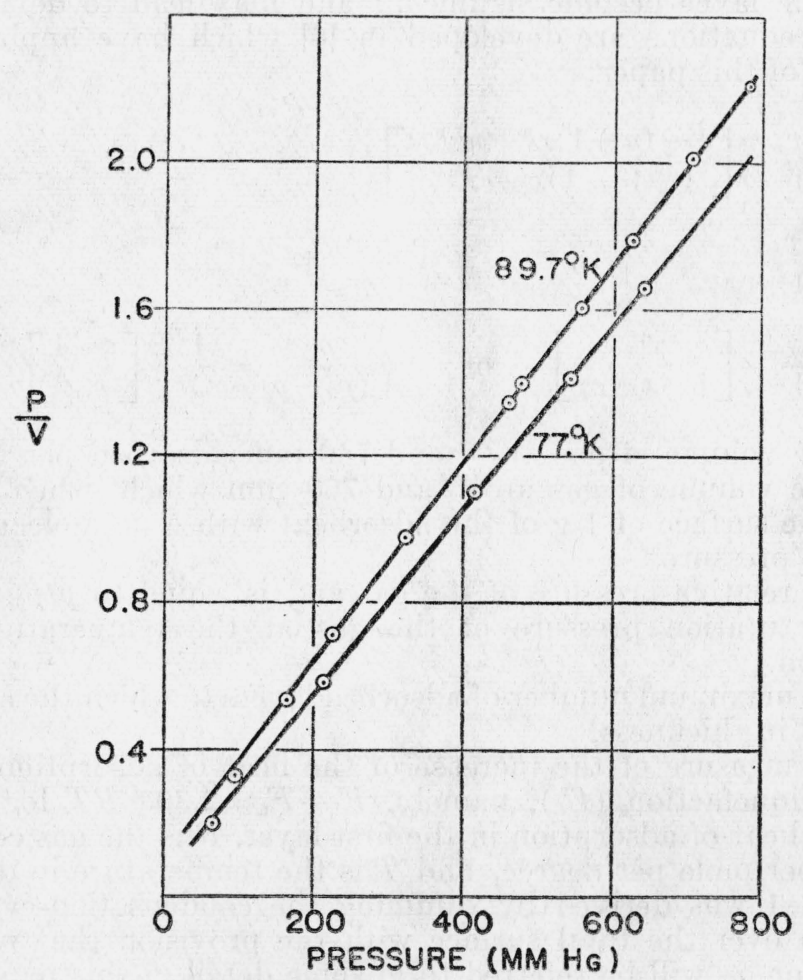

Figure 9.-The linear plot of $p / V$ against $p$ for nitrogen adsorbed on No. 1 sample of coconut-shell charcoal at $89.7^{\circ}$ and $77^{\circ} \mathrm{K}$.

Note that the maximum pressure for the $89.7^{\circ} \mathrm{K}$ line corresponds to a relative pressure of about 0.3 , but the point at $650 \mathrm{~mm}$ on the $77^{\circ} \mathrm{K}$ line corresponds to a relative pressure of 0.85 .

ing carbons other than bone char. This consists in substituting the experimental values of $V$ (for example at $x=0.1$ and 0.2 ) into eq 1 . Upon assuming different values for $n$, the resulting calculated values for $v_{m}$ and $c$ are tested by comparing the remaining part of the adsorption isotherm with the experimental data. Figure 11 illustrates the results for new bone char 2 and figure 12 for service bone char 3 . As may be seen from these plots, it is possible to reproduce the experimental isotherm for a particular set of constants up to a relative pressure of about 0.5 to 0.6 . Above this pressure the observed adsorption always increases faster than the calculated values. The sets of values for $n, v_{m}$, and $c$ giving the best agreement are entered in table 1 and will be discussed in the next section.

For the decolorizing carbons other than bone char, the linear plot of $p / V\left(p_{0}-p\right)$ against $p / p_{0}$ does not hold as it did for the bone chars. 
The plot of $p / V$ against $p$, which is the test for unimolecular adsorption, also is not linear. The explanation is that the values for $n$ are approximately 1.5 or 2 and for these small values eq 3 cannot hold. Consequently $v_{m}$ and $c$ must be calculated by substituting the experimental values of $V$ and $x$ into eq 1 , assuming different values for $n$, in the manner described above. Figure 13 illustrates the results for carbon 6 . When $n$ is assumed to be 1.5 , the values obtained are $v_{m}=$ 141 and $c=58$; when $n=2, v_{m}=129$ and $c=106$; finally when $n=3$, $v_{m}=119$ and $c=510$. The value of $n=2$ yields a calculated curve which is in best agreement with experiment up to a relative pressure

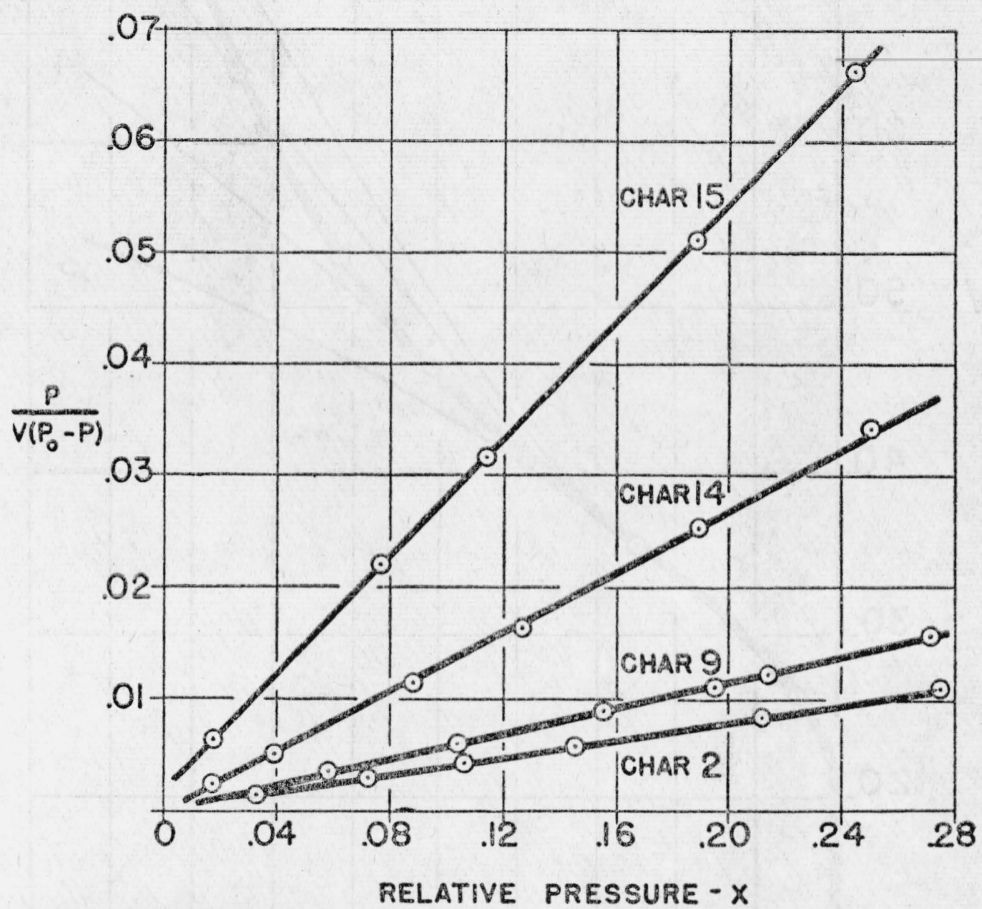

FrguRe 10.-The linear plot of $p / V\left(p_{0}-p\right)$ against $p / p_{0}$ for nitrogen adsorbed on four samples of bone chars at $90^{\circ} \mathrm{K}$.

of about 0.4 to 0.5 . A value of 2.2 would, perhaps, give a little better agreement; however, for the present no attempt has been made to establish the absolute value of $n$ with greater accuracy. A value of $n=2.2$ has been reported by Brunauer, Emmett, and Teller [6] for a sample of activated carbon designated as granular Darco G. In connection with this behavior, these authors [6] have pointed out that as long as the capillaries of an adsorbent are fairly uniform in diameter, eq 1 can describe the entire course of the isotherm with a fair degree of accuracy. Should the size of the pores in an adsorbent vary considerably from the average, the experimental points will fall above the theoretical curve at higher pressures and below the curve at lower pressures. They propose an equation to take care of the varying size of capillaries, but its practical use is inexpedient because of the large number of constants. The subject of capillaries is further discussed in section VII. 
206 Journal of Research of the National Bureau of Standards

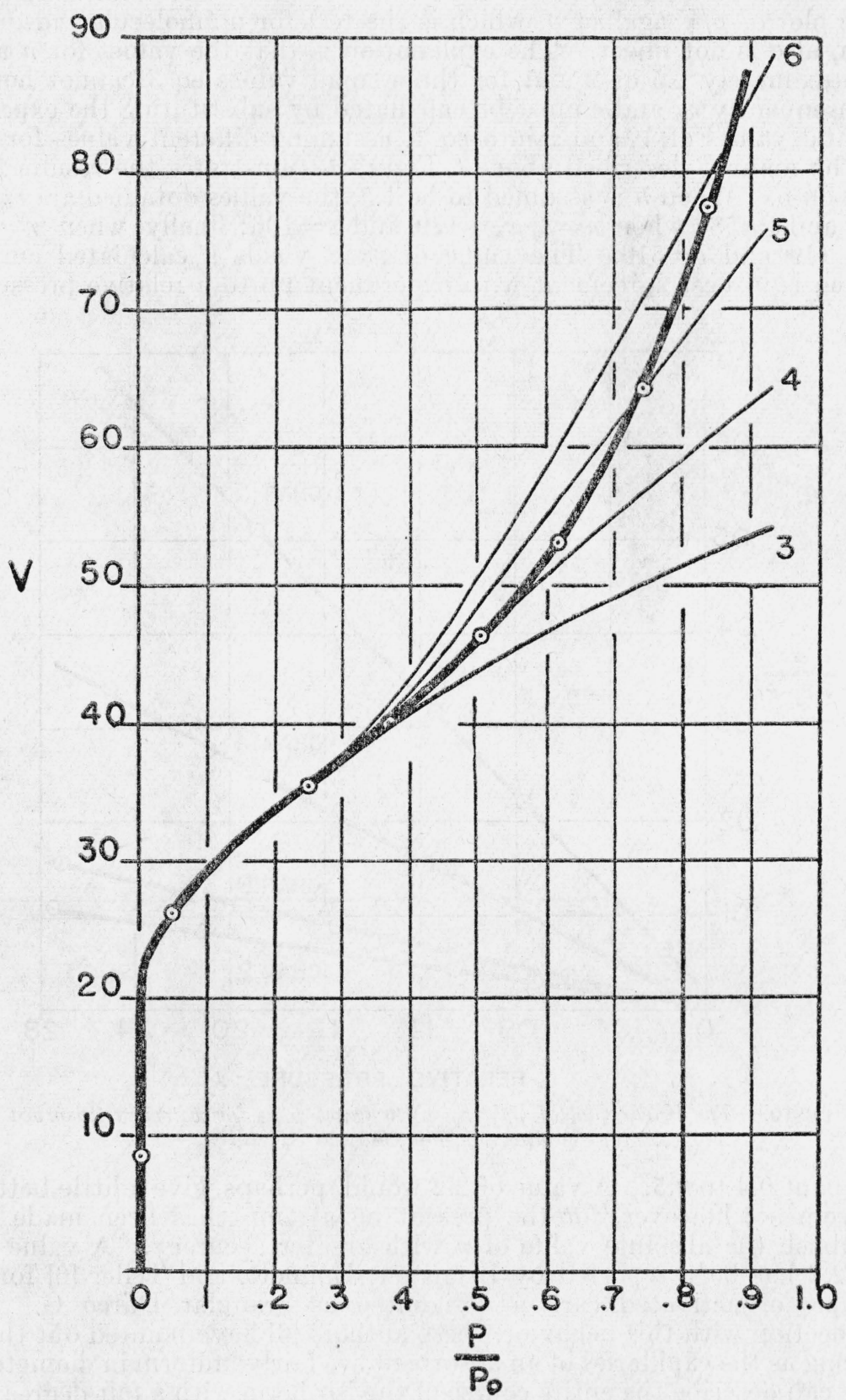

FigORE 11.-Observed and calculated isotherms of nitrogen adsorbed on new bone-char sample 2 at $77^{\circ} \mathrm{K}$.

Experimental points are in circles, and isotherms are calculated at values of $n=3,4,5$, and 6 . The volume adsorbed, $V$, is expressed in milliliters per gram of adsorbent. 


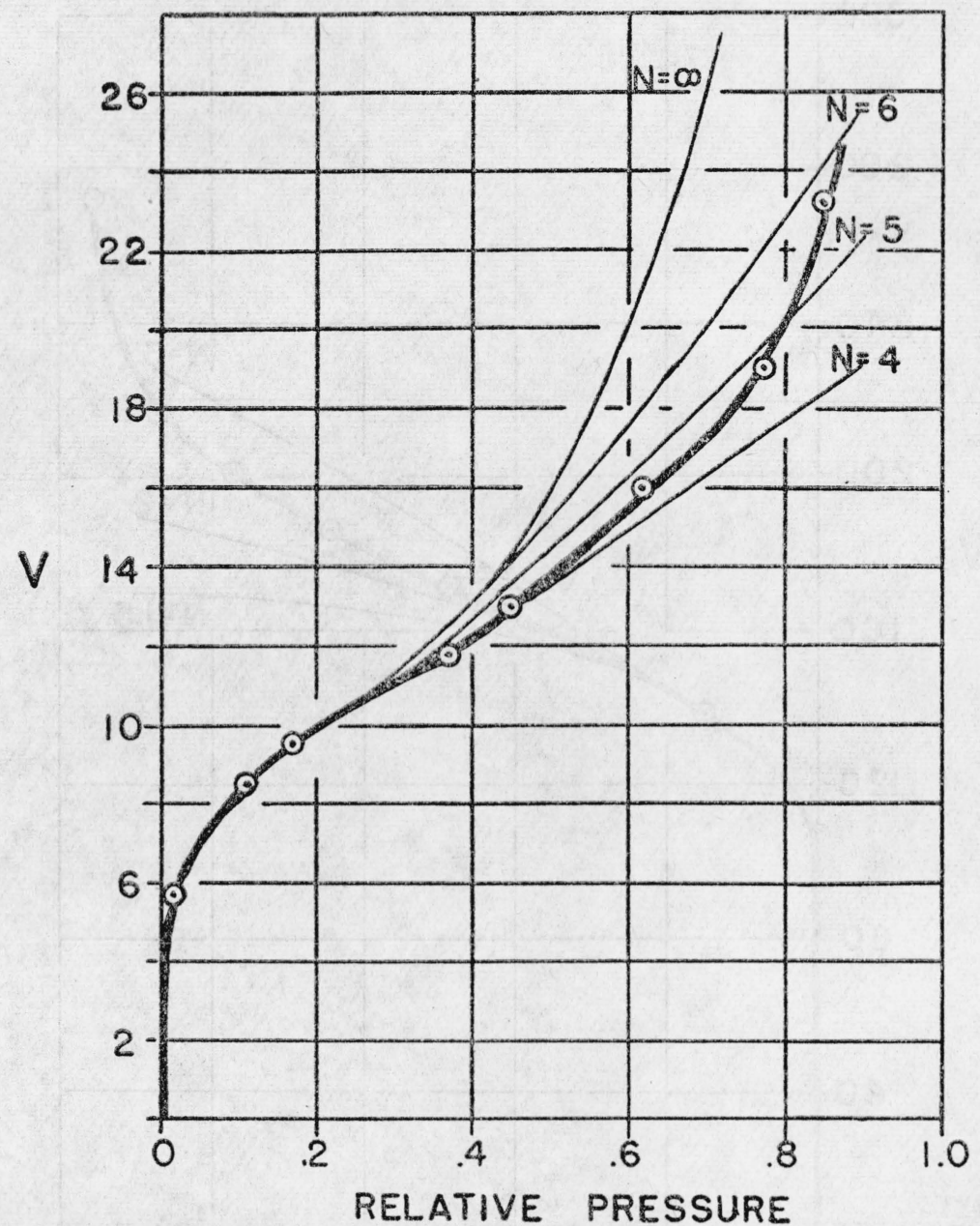

FIGURE 12.-Observed and calculated isotherms of nitrogen adsorbed on service bone-char sample No. 8 at $7 \gamma^{\circ} K$.

Experimental pointsare in circles, and isotherms are calculated at values of $n=4,5,6$, and $\infty$. The volume adsorbed, $V$, is expressed in milliliters per gram of adsorbent.

It may be observed that the calculated isotherms are more sensitive to a unit change in $n$ when $n$ is small than when $n$ is large. This may be seen by comparing figures 11 and 13 . It is surprising that the isotherms of a new bone black (fig. 11) and a service bone black (fig. 12) may be fitted by the same value of $n$. The progressive aging of a bone black, with its accompanying decrease in efficiency, has been attributed to the accumulation of insoluble salts. However, if this deposition occurred in the larger pores, the distribution of pore sizes in new and used bone-black samples would be essentially unchanged for gas adsorption. 


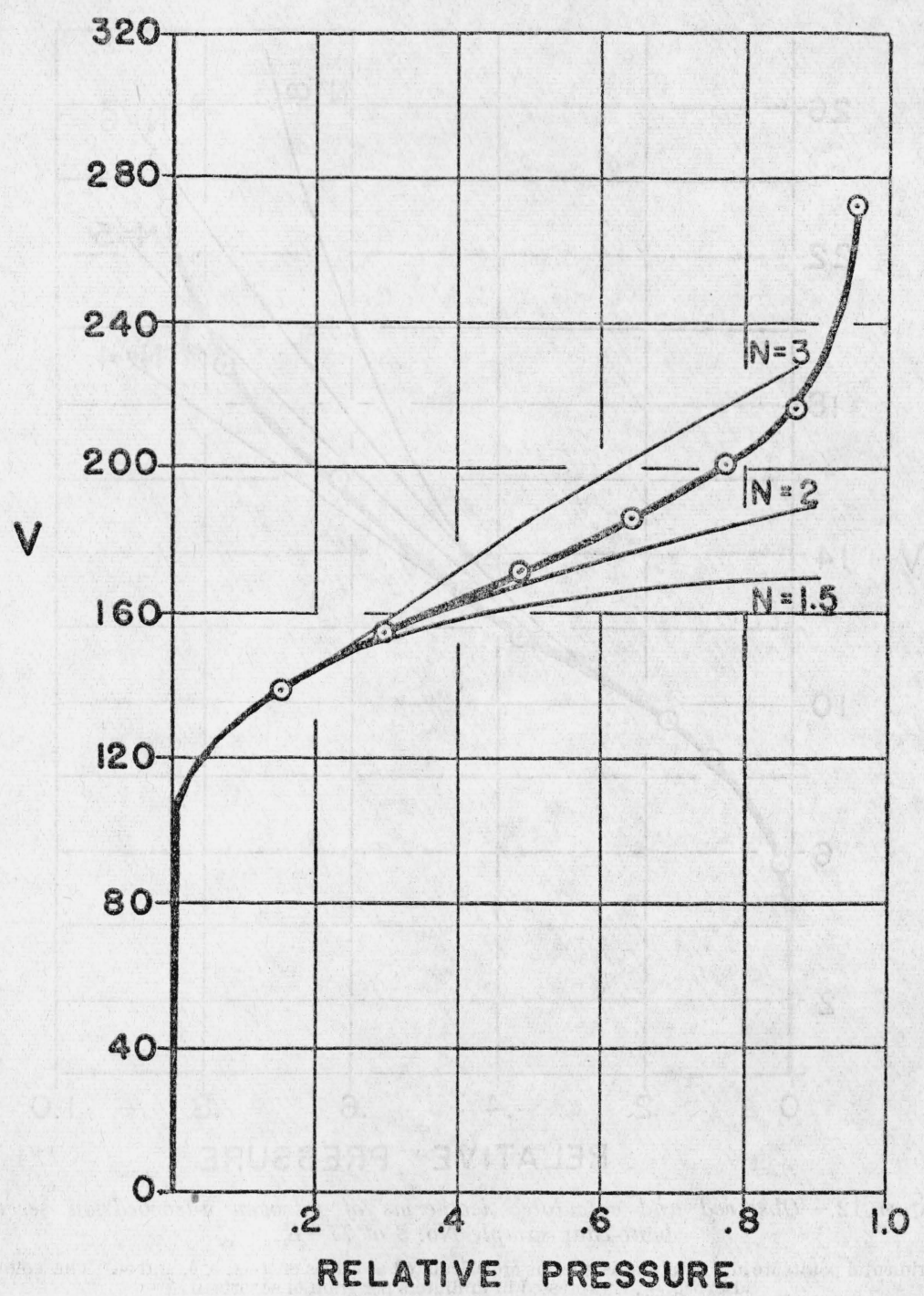

FigURE 13.- Observed and calculated isotherms of nitrogen adsorbed on the No. 6 activated carbon at $77^{\circ} \mathrm{K}$.

Experimental points are in circles, and curves are calculated at values of $n=1.5,2$, and 3. The volum adsorbed, $V$, is expressed in milliliters per $\mathrm{g}$ of adsorbent. For $n=1.5, v_{m}=141$, and $c=58$; when $n=2$, $v_{m}=129$, and $c=106 ;$ when $n=3, v_{m}=119$, and $c=510$.

\section{DISCUSSION OF TABLE OF RESULTS}

Table 1 summarizes the results for the surface calculations. As previously mentioned, $v_{m}$ is the volume of nitrogen measured at $0^{\circ} \mathrm{C}$ and $760 \mathrm{~mm}$ which, when adsorbed, covers the surface of $1 \mathrm{~g}$ of sample with a unimolecular layer. The first group contains the data for new bone-char samples from different manufacturers. The values for $n$ are either 4 or 5 . In the second group are the bone chars which have been in service in cane-sugar refineries, and for these, too, $n$ is either 
4 or 5 . The third group includes the vegetable and the activated carbons, and for these $n$ is either 1.5 or 2. The two charcoal samples in group 4 are definitely characterized by $n=1$. Finally, for the carbon black sample, $n$ is about 4 , but for pressures higher than $x=0.6, n$ most probably increases.

In order to calculate the area of the surface from $v_{m}$, it is necessary to know how the nitrogen molecules are packed on the adsorbing surface, since its area is simply the product of the number of adsorbed molecules times the average area that each molecule occupies in the adsorbed state. This procedure has been discussed by Emmett and Brunauer [4] and by Brunauer, Emmett, and Teller [6], who considered liquidlike packing as the best approximation that is available at present. The uncertainty in the knowledge of the packing factor constitutes the main limitation on the accuracy of this method of surface measurement. For comparative purposes the error introduced by this uncertainty is cancelled. A rough estimate of the accuracy would indicate a value of 5 percent for relative purposes, usually much better, but about 20 percent for absolute accuracy. However, the agreement with the electron-microscope data for the carbon blacks, as mentioned in section II-1, indicates much better accuracy than 20 percent for particles which may be considered relatively nonporous. There is no method at present to check the surtace calculations for highly porous materials. However, there does not appear to be any reason for assuming unique adsorption behavior for highly porous materials in the regions in which capillarity effects, such as hysteresis, are excluded.

By assuming hexagonal close-packing for liquid nitrogen, one obtains for the diameter, $D$, of a single $\mathrm{N}_{2}$ molecule:

$$
D^{3}=\frac{6 v(0.74)}{N_{A} \pi},
$$

where $v$ is the molar volume of the liquid in milliliters, $N_{A}$ is Avogadro's number, the factor 0.74 is the fraction of the total space filled by spheres hexagonally close-packed. Thus $D$ is the diameter in centimeters of an isolated sphere. When the surface is covered, hexagonal close-packing in two dimensions is assumed to occur, and in this case the fraction of the surface covered by the projection of the spheres on the surface is 0.908 . The surface, $S$, in square meters, covered by $1 \mathrm{ml}$ of gas becomes:

$$
S=2.705 \times 10^{19}\left[\frac{1}{0.908}\right] \frac{\pi}{4}\left[\frac{6 v(0.74)}{N_{A} \pi}\right]=0.412 v^{2 / 3} .
$$

$2.705 \times 10^{19}$ is the number of gas molecules per milliliter. The molar volume for liquid nitrogen was obtained from the International Critical Tables. A plot was made of $S$ against $T$ in order to facilitate the calculation for the surface of each sample at the particular temperature of the experiment. For example, at $90.0^{\circ} \mathrm{K}, S=4.61_{5} \mathrm{~m}^{2} / \mathrm{ml} \mathrm{N}_{2}$, and at $77.0^{\circ} \mathrm{K}, S=4.37_{3} \mathrm{~m}^{2} / \mathrm{ml} \mathrm{N}_{2}$.

The results of the surface calculation are shown in column 7 of table 1. The surfaces of new bone chars vary only from 104 to 120 $\mathrm{m}^{2} / \mathrm{g}$ for four samples of different manufacturers, a fact which is indicative of the uniformity of the current production of bone char. Bone char 9 of limited service shows a surface of 83.5; the char, 8, 


\section{Journal of Research of the National Bureau of Standards}

of gray appearance is next with a surface of 60.2 ; three other service chars show surfaces of $40.1,37.2$, and 35.6 ; a spent char shows a surface of 18.0. We may therefore draw a parallel for these bone chars between the surface areas and the efficiencies with which the samples are known to decolorize sugar liquors. However, it should be pointed out at once that the surface available to nitrogen molecules is not that available for adsorption from solution. The ratios between the total surfaces of materials of similar origin may, nevertheless, be the same as the ratios of the corresponding surfaces available to solution adsorption.

It is to be noted that the wide spread in the values for $c$ in various experiments with the same char does not imply corresponding uncertainties in $E_{1}-E_{L}$. This is due to the logarithmic relationship $E_{1}-E_{L}=2.3 \mathrm{RT} \log c$.

TABLE 1.-Results of the surface calculations for bone chars and other carbonaceous adsorbents

\begin{tabular}{|c|c|c|c|c|c|c|}
\hline Type of char & $\begin{array}{l}\text { Experi- } \\
\text { ment No. }\end{array}$ & $\begin{array}{l}\text { Temper- } \\
\text { ature }\end{array}$ & $n$ & $v_{m^{1}}$ & $S$ & $c$ \\
\hline \multicolumn{7}{|c|}{ GROUP I } \\
\hline $\begin{array}{l}\text { New bone char } 2 \\
\text { Do } \\
\text { Do } \\
\text { Do } \\
\text { Do } \\
\text { Do }\end{array}$ & $\begin{array}{l}12-\mathrm{a} \\
14-\mathrm{a} \\
19-\mathrm{c} \\
16-\mathrm{e} \\
1 \\
12-\mathrm{e}\end{array}$ & $\begin{array}{l}{ }^{\circ} K \\
76.4 \\
76.3 \\
90.0 \\
89.9 \\
89.5 \\
89.3\end{array}$ & $\begin{array}{l}4 \\
4 \\
4 \\
4 \\
4 \\
4\end{array}$ & $\begin{array}{r}m l \text { at } S T P^{2} \\
27.2 \\
27.6 \\
25.4 \\
26.0 \\
25.5 \\
25.8\end{array}$ & $\begin{array}{r}m^{2} / g \\
119 \\
120 \\
117 \\
120 \\
118 \\
119\end{array}$ & $\begin{array}{l}208 \\
487 \\
216 \\
202 \\
105 \\
187\end{array}$ \\
\hline $\begin{array}{l}\text { New bone char } C \\
\text { Do }\end{array}$ & $\begin{array}{l}21-\mathrm{a} \\
21-\mathrm{b}\end{array}$ & $\begin{array}{l}77.3 \\
90.1\end{array}$ & $\begin{array}{l}5 \\
5\end{array}$ & $\begin{array}{l}24.6 \\
22.6\end{array}$ & $\begin{array}{l}108 \\
104\end{array}$ & $\begin{array}{l}138 \\
163\end{array}$ \\
\hline $\begin{array}{l}\text { New bone char } B \\
\text { Do }\end{array}$ & $\begin{array}{l}21-a \\
21-b\end{array}$ & $\begin{array}{l}77.3 \\
90.1\end{array}$ & $\begin{array}{l}5 \\
5\end{array}$ & $\begin{array}{l}23.3 \\
22.5\end{array}$ & $\begin{array}{l}102 \\
104\end{array}$ & $\begin{array}{l}291 \\
141\end{array}$ \\
\hline $\begin{array}{l}\text { New bone char } 16 \\
\text { Do } \\
\text { Do }\end{array}$ & $\begin{array}{l}20-8 \\
13 \\
20-j\end{array}$ & $\begin{array}{l}77.2 \\
89.3 \\
90.4\end{array}$ & $\begin{array}{l}5 \\
5 \\
5\end{array}$ & $\begin{array}{l}23.9 \\
22.6 \\
21.7\end{array}$ & $\begin{array}{l}104 \\
104 \\
101\end{array}$ & $\begin{array}{l}466 \\
163 \\
163\end{array}$ \\
\hline \multicolumn{7}{|c|}{ GROUP II } \\
\hline $\begin{array}{l}\text { Service bone char } 3 \\
\text { Do } \\
\text { Do } \\
\text { Do } \\
\text { Do }\end{array}$ & $\begin{array}{l}12-8 \\
14-8 \\
16-e \\
19-c \\
12-e\end{array}$ & $\begin{array}{l}76.4 \\
76.3 \\
89.7 \\
90.0 \\
89.3\end{array}$ & $\begin{array}{l}4 \\
4 \\
4 \\
4 \\
4\end{array}$ & $\begin{array}{l}8.17 \\
9.39 \\
7.51 \\
8.37 \\
7.85\end{array}$ & $\begin{array}{l}35.7 \\
41.0 \\
34.6 \\
38.6 \\
36.1\end{array}$ & $\begin{array}{r}137 \\
760 \\
91 \\
99 \\
186\end{array}$ \\
\hline $\begin{array}{l}\text { Service bone char } 8 \text { (gray) } \\
\text { Do }\end{array}$ & $\begin{array}{l}17-1 \\
17-\mathrm{a}\end{array}$ & $\begin{array}{l}77.0 \\
89.8\end{array}$ & $\begin{array}{l}4 \\
4\end{array}$ & $\begin{array}{l}13.75 \\
13.06\end{array}$ & $\begin{array}{l}60.2 \\
60.2\end{array}$ & $\begin{array}{l}370 \\
160\end{array}$ \\
\hline $\begin{array}{l}\text { Service bone char } 9 \\
\text { Do }\end{array}$ & $\begin{array}{l}17-1 \\
17-8\end{array}$ & $\begin{array}{l}77.0 \\
89.8\end{array}$ & $\begin{array}{l}4 \\
4\end{array}$ & $\begin{array}{l}19.28 \\
17.97\end{array}$ & $\begin{array}{l}84.4 \\
82.8\end{array}$ & $\begin{array}{l}147 \\
142\end{array}$ \\
\hline $\begin{array}{l}\text { Service bone char } 14 \\
\text { Do } \\
\text { Do } \\
\text { Do }\end{array}$ & $\begin{array}{l}17-1 \\
17-8 \\
8 \\
10\end{array}$ & $\begin{array}{l}77.2 \\
89.7 \\
89.5 \\
89.4\end{array}$ & $\begin{array}{l}5 \\
5 \\
5 \\
5\end{array}$ & $\begin{array}{l}9.4 \\
8.5 \\
8.51 \\
8.89\end{array}$ & $\begin{array}{l}41.2 \\
39.2 \\
39.2 \\
40.9\end{array}$ & $\begin{array}{r}169 \\
100 \\
95 \\
105\end{array}$ \\
\hline $\begin{array}{l}\text { Service char } 12 \ldots \\
\text { Do }\end{array}$ & $\begin{array}{r}22 \\
1\end{array}$ & $\begin{array}{l}77.8 \\
89.5\end{array}$ & $\begin{array}{l}4 \\
4\end{array}$ & $\begin{array}{l}8.55 \\
7.30\end{array}$ & $\begin{array}{l}37.5 \\
33.7\end{array}$ & $\begin{array}{l}200 \\
240\end{array}$ \\
\hline $\begin{array}{l}\text { Spent ehar } 15 \\
\text { Do }\end{array}$ & $\begin{array}{l}22 \\
10\end{array}$ & $\begin{array}{l}77.8 \\
89.4\end{array}$ & $\begin{array}{l}4 \\
4\end{array}$ & $\begin{array}{l}4.25 \\
3.82\end{array}$ & $\begin{array}{l}18.5 \\
17.6\end{array}$ & $\begin{array}{l}177 \\
115\end{array}$ \\
\hline
\end{tabular}

1 Adsorption per gram of adsorbent.

3 Standard temperature and pressure. 
TABLE 1.-Results of the surface calculations for bone chars and other carbonaceous adsorbents-Continued

\begin{tabular}{|c|c|c|c|c|c|c|}
\hline Type of char & Experi- & $\begin{array}{l}\text { Temper- } \\
\text { ature }\end{array}$ & $n$ & $n_{m^{1}}$ & $S$ & $c$ \\
\hline \multicolumn{7}{|c|}{ GROUP III } \\
\hline & & ${ }^{\circ} \mathrm{K}$ & & $m l$ at $S T P^{3}$ & $m^{2} / g$ & \\
\hline $\begin{array}{l}\text { Vegetable carbon } 4 \\
\text { Do } \\
\text { Do }\end{array}$ & $\begin{array}{l}15-\mathrm{a} \\
15-\mathrm{i} \\
18-\mathrm{d}\end{array}$ & $\begin{array}{l}76.7 \\
89.6 \\
89.9\end{array}$ & $\begin{array}{l}1.5 \\
1.5 \\
1.5\end{array}$ & $\begin{array}{l}214 \\
200 \\
201\end{array}$ & $\begin{array}{l}937 \\
923 \\
930\end{array}$ & $\begin{array}{l}164 \\
280 \\
317\end{array}$ \\
\hline $\begin{array}{l}\text { Vegetable carbon } 5 \\
\text { Do } \\
\text { Do }\end{array}$ & $\begin{array}{l}15-\mathrm{a} \\
15-\mathrm{i} \\
18-\mathrm{d}\end{array}$ & $\begin{array}{l}76.7 \\
89.6 \\
89.9\end{array}$ & $\begin{array}{l}2.0 \\
2.0 \\
2.0\end{array}$ & $\begin{array}{l}210 \\
180 \\
184\end{array}$ & $\begin{array}{l}925 \\
830 \\
852\end{array}$ & $\begin{array}{l}100 \\
184 \\
207\end{array}$ \\
\hline $\begin{array}{l}\text { Activated carbon } 6 \\
\text { Do } \\
\text { Do }\end{array}$ & $\begin{array}{l}15-\mathrm{a} \\
15-\mathrm{i} \\
18-\mathrm{d}\end{array}$ & $\begin{array}{l}76.7 \\
89.6 \\
89.9\end{array}$ & $\begin{array}{l}2.0 \\
2.0 \\
2.0\end{array}$ & $\begin{array}{r}129 \\
93 \\
118\end{array}$ & $\begin{array}{l}563 \\
432 \\
548\end{array}$ & $\begin{array}{l}106 \\
146 \\
360\end{array}$ \\
\hline $\begin{array}{l}\text { Activated carbon } 19 \\
\text { Do }\end{array}$ & $\begin{array}{l}20-a \\
20-\mathrm{j}\end{array}$ & $\begin{array}{l}77.3 \\
90.4\end{array}$ & $\begin{array}{l}2.0 \\
2.0\end{array}$ & $\begin{array}{l}305 \\
279\end{array}$ & $\begin{array}{l}1,340 \\
1,290\end{array}$ & $\begin{array}{l}200 \\
165\end{array}$ \\
\hline $\begin{array}{l}\text { Activated carbon } 20 \\
\text { Do }\end{array}$ & $\begin{array}{l}20-\mathrm{a} \\
20-\mathrm{j}\end{array}$ & $\begin{array}{l}77.3 \\
90.4\end{array}$ & $\begin{array}{l}2.0 \\
2.0\end{array}$ & $\begin{array}{l}115 \\
103\end{array}$ & $\begin{array}{l}506 \\
478\end{array}$ & $\begin{array}{l}100 \\
220\end{array}$ \\
\hline $\begin{array}{l}\text { Activated carbon } 18 \\
\text { Do }\end{array}$ & $\begin{array}{l}23 \\
11\end{array}$ & $\begin{array}{l}77.6 \\
89.3\end{array}$ & $\begin{array}{l}1.5 \\
1.5\end{array}$ & $\begin{array}{l}328 \\
300\end{array}$ & $\begin{array}{l}1,440 \\
1,380\end{array}$ & $\begin{array}{l}216 \\
178\end{array}$ \\
\hline \multicolumn{7}{|c|}{ GROUP IV } \\
\hline $\begin{array}{l}\text { Coconut charcoal 1... } \\
\text { Do } \\
\text { Do } \\
\text { Do } \\
\text { Do } \\
\text { Do }\end{array}$ & $\begin{array}{l}12-a \\
14-a \\
12-e \\
16-a \\
16-e \\
19-\mathrm{c}\end{array}$ & $\begin{array}{l}76.4 \\
76.3 \\
89.3 \\
89.6 \\
89.7 \\
90.0\end{array}$ & \begin{tabular}{l|}
1 \\
1 \\
1 \\
1 \\
1 \\
1
\end{tabular} & $\begin{array}{l}425 \\
430 \\
364 \\
367 \\
370 \\
377\end{array}$ & $\begin{array}{l}1,860 \\
1,880 \\
1,675 \\
1,680 \\
1,700 \\
1,730\end{array}$ & $\begin{array}{r}25 \\
-74 \\
70 \\
72 \\
83\end{array}$ \\
\hline $\begin{array}{c}\text { Coconut charcoal 17. } \\
\text { Do }\end{array}$ & $\begin{array}{l}24-\mathrm{b} \\
24-\mathrm{c}\end{array}$ & $\begin{array}{l}90.0 \\
77.6\end{array}$ & $\begin{array}{l}1 \\
1\end{array}$ & $\begin{array}{l}293 \\
323\end{array}$ & $\begin{array}{l}1,350 \\
1,420\end{array}$ & $\begin{array}{r}64 \\
107\end{array}$ \\
\hline \multicolumn{7}{|c|}{ GROUP V } \\
\hline $\begin{array}{l}\text { Carbon black } A \\
\text { Do }\end{array}$ & $\begin{array}{l}24-\mathrm{a} \\
24-\mathrm{b}\end{array}$ & $\begin{array}{l}77.6 \\
90.0\end{array}$ & $\begin{array}{l}4 \\
4\end{array}$ & $\begin{array}{l}25.52 \\
24.27\end{array}$ & $\begin{array}{l}112 \\
112\end{array}$ & $\begin{array}{l}168 \\
111\end{array}$ \\
\hline $\begin{array}{r}\text { Petroleum coke 13... } \\
\text { Do }\end{array}$ & $\begin{array}{r}23 \\
5\end{array}$ & $\begin{array}{l}77.6 \\
89.8\end{array}$ & 2 & $\begin{array}{r}0.12 \\
.11\end{array}$ & $\begin{array}{r}0.53 \\
.51\end{array}$ & 100 \\
\hline
\end{tabular}

${ }_{1}^{1}$ Adsorption per gram of adsorbent.

2 Standard temperature and pressure.

\section{ISOTHERMS REDUCED TO UNIT SURFACE}

The isotherms for the group of bone chars show wide variance in the amount of nitrogen adsorbed. By referring to figure 3 and to table 2, it may be seen that the volumes of nitrogen adsorbed at $x=0.2$, for example, are $33.4,23.3,11.7$, and $5.13 \mathrm{ml}$ for bone chars $2,9,14$, and 15 , respectively. The corresponding values for $v_{m}$, as given in table 1, may be seen to vary between 22.6 for char 2 and 4.25 for char 15 , which is greater than a fivefold variation. Despite these large differences, it will be seen from the following calculation that the amount of nitrogen adsorbed per unit surface of each sample is the same for all the bone chars at a given relative pressure of the nitrogen. This is true to within the over-all error of the experiments at relative pressures from $x=0.1$ to $x=0.6$. 
The data in table 2 illustrate this correlation for a number of bone chars at $77^{\circ} \mathrm{K}$. The values for $V$ were obtained from the experimental isotherms for the given values of $x$. The definitions of $x, V$, and $v_{m}$ are as previously used. Figure 14 shows this same conclusion in a graphical manner, an average curve being drawn through the points indicated. At relative pressures of $x=0.6$ and higher, individual differences begin to be manifested. At higher pressures slight differences in the distribution of the wider pores bring about differences in the amount adsorbed. But below $x=0.6$ the quantity of nitrogen adsorbed (at a given value of $x$ ) depends simply on the area of the surface available to the nitrogen. As indicated in the tables, the total spread of the values for $V / v_{m}$ is rarely more than 5 percent.

TABLE 2.-Value of $V / v_{m}$ for the adsorption of nitrogen on bone chars at $77^{\circ} \mathrm{K}$

[Values given under $V$ are in milliliters at STP]

\begin{tabular}{|c|c|c|c|c|c|c|c|c|c|c|}
\hline \multirow{2}{*}{$x$} & \multicolumn{2}{|c|}{ New char 2} & \multicolumn{2}{|c|}{ New char 2} & \multicolumn{2}{|c|}{ Service char 9} & \multicolumn{2}{|c|}{$\begin{array}{c}\text { Service char } 8 \\
\text { (gray) }\end{array}$} & \multicolumn{2}{|c|}{ Service char 3} \\
\hline & $V($ obs.) & $V / v_{m}$ & $V$ (obs.) & $V / v_{m}$ & $V$ (obs.) & $V / v_{m}$ & $V$ (obs.) & $V / v_{m}$ & $V$ (obs.) & $V / v_{m}$ \\
\hline $\begin{array}{l}0.1 \\
0.2 \\
0.3 \ldots \\
0.4 \\
0.5 \\
0.6 \\
0.7 \ldots\end{array}$ & $\begin{array}{l}29.0 \\
33.4 \\
37.4 \\
41.5 \\
46.3 \\
51.8 \\
60.2\end{array}$ & $\begin{array}{l}1.06 \\
1.23 \\
1.37 \\
1.52 \\
1.70 \\
1.90 \\
2.21\end{array}$ & $\begin{array}{l}30.0 \\
34.2 \\
38.2 \\
42.2 \\
46.5 \\
52.2 \\
60.2\end{array}$ & $\begin{array}{l}1.08 \\
1.24 \\
1.38 \\
1.53 \\
1.68 \\
1.89 \\
2.18\end{array}$ & $\begin{array}{l}20.2 \\
23.3 \\
26.5 \\
29.7 \\
33.7 \\
38.4 \\
44.8\end{array}$ & $\begin{array}{l}1.05 \\
1.21 \\
1.37 \\
1.54 \\
1.75 \\
1.99 \\
2.32\end{array}$ & $\begin{array}{l}14.9 \\
17.0 \\
19.0 \\
21.5 \\
24.2 \\
27.0 \\
31.3\end{array}$ & $\begin{array}{l}1.08 \\
1.23 \\
1.37 \\
1.55 \\
1.75 \\
1.95 \\
2.26\end{array}$ & $\begin{array}{l}10.2 \\
11.6 \\
13.0 \\
14.3 \\
15.7 \\
17.5 \\
19.8\end{array}$ & $\begin{array}{l}1.08 \\
1.23 \\
1.38 \\
1.52 \\
1.67 \\
1.86 \\
2.11\end{array}$ \\
\hline & \multicolumn{2}{|c|}{$\begin{array}{c}\text { Exp. 12-a } \\
n=4 \\
v_{m}=27.24\end{array}$} & \multicolumn{2}{|c|}{$\begin{array}{c}\text { Exp. } 14-\mathrm{a} \\
\begin{array}{c}n=4 \\
v_{m}=27.60\end{array}\end{array}$} & \multicolumn{2}{|c|}{$\begin{array}{c}\text { Exp. } 17-1 \\
n=4 \\
v_{m}=19.28\end{array}$} & \multicolumn{2}{|c|}{$\begin{array}{c}\text { Exp. } 17-1 \\
n=4 \\
v_{m}=13.8\end{array}$} & \multicolumn{2}{|c|}{$\begin{array}{c}\text { Exp. } 14-\mathrm{a} \\
n=4 \\
v_{m}=9.39\end{array}$} \\
\hline \multirow{2}{*}{$x$} & \multicolumn{2}{|c|}{ Service char 14} & \multicolumn{2}{|c|}{ Service char 12} & \multicolumn{2}{|c|}{ Service char 3} & \multicolumn{2}{|c|}{ Spent char 15} & \multicolumn{2}{|c|}{ New char 16} \\
\hline & $V$ (obs.) & $V / v_{m}$ & $V($ obs.) & $V / v_{m}$ & $V$ (obs.) & $V / v_{m}$ & $V$ (obs.) & $V / v_{m}$ & $V($ obs. $)$ & $V / v_{m}$ \\
\hline \multirow[t]{2}{*}{$\begin{array}{l}0.1 \\
0.2 \ldots \\
0.3 \\
0.4 \\
0.5 \\
0.6 \\
0.7\end{array}$} & $\begin{array}{l}10.3 \\
11.7 \\
13.6 \\
15.8 \\
18.3 \\
20.8 \\
23.7\end{array}$ & $\begin{array}{l}1.06 \\
1.21 \\
1.40 \\
1.63 \\
1.89 \\
2.14 \\
2.45\end{array}$ & $\begin{array}{r}9.1 \\
10.5 \\
11.7 \\
13.1 \\
14.6 \\
16.8 \\
19.7\end{array}$ & $\begin{array}{l}1.06 \\
1.23 \\
1.37 \\
1.54 \\
1.71 \\
1.97 \\
2.31\end{array}$ & $\begin{array}{r}8.5 \\
10.0 \\
11.1 \\
12.3 \\
13.8 \\
15.5 \\
17.3\end{array}$ & $\begin{array}{l}1.04 \\
1.22 \\
1.36 \\
1.51 \\
1.69 \\
1.90 \\
2.12\end{array}$ & $\begin{array}{l}4.5 \\
5.13 \\
5.87 \\
6.40 \\
7.12 \\
8.25 \\
9.78\end{array}$ & $\begin{array}{l}1.06 \\
1.21 \\
1.38 \\
1.51 \\
1.67 \\
1.94 \\
2.30\end{array}$ & $\begin{array}{l}26.3 \\
29.9 \\
33.7 \\
38.2 \\
43.0 \\
48.9 \\
58.7\end{array}$ & $\begin{array}{l}1.09 \\
1.24 \\
1.40 \\
1.59 \\
1.79 \\
2.04 \\
2.44\end{array}$ \\
\hline & \multicolumn{2}{|c|}{$\begin{array}{c}\text { Exp. } 17-1 \\
n=5 \\
v_{m}=9.68\end{array}$} & \multicolumn{2}{|c|}{$\begin{array}{c}\text { Exp. } 22 \\
n=4 \\
v_{m}=8.53\end{array}$} & \multicolumn{2}{|c|}{$\begin{array}{c}\text { Exp. } 12-\mathrm{a} \\
n=4 \\
v_{m}=8.17\end{array}$} & \multicolumn{2}{|c|}{$\begin{array}{c}\text { Exp. } 22 \\
n=4 \\
v_{m}=4.25\end{array}$} & \multicolumn{2}{|c|}{$\begin{array}{c}\text { Exp. } 20-\mathrm{a} \\
n=5 \\
v_{m}=23.98\end{array}$} \\
\hline \multirow[b]{2}{*}{$x$} & \multicolumn{2}{|c|}{ New char $C$} & \multicolumn{2}{|c|}{ New char $B$} & \multicolumn{3}{|c|}{ Spread of $V / v_{m}$ for $n=4$} & \multicolumn{3}{|c|}{ Spread of $V / v_{m}$ for $n=5$} \\
\hline & $V$ (obs.) & $V / v_{m}$ & $V$ (obs.) & $V / v_{m}$ & Min. & Max. & $\begin{array}{l}\text { Devia- } \\
\text { tion }\end{array}$ & Min. & Max. & $\begin{array}{l}\text { Devia- } \\
\text { tion }\end{array}$ \\
\hline $\begin{array}{l}0.1 \\
0.2 \\
0.3 \\
0.4 \\
0.5 \\
0.6 \\
0.7 \ldots\end{array}$ & $\begin{array}{l}25.7 \\
29.8 \\
34.3 \\
39.0 \\
44.1 \\
50.2 \\
58.6\end{array}$ & $\begin{array}{l}1.05 \\
1.21 \\
1.39 \\
1.58 \\
1.80 \\
2.04 \\
2.39\end{array}$ & $\begin{array}{l}25.0 \\
28.7 \\
32.6 \\
37.1 \\
42.0 \\
48.0 \\
56.8\end{array}$ & $\begin{array}{l}1.07 \\
1.23 \\
1.40 \\
1.59 \\
1.80 \\
2.06 \\
2.44\end{array}$ & $\begin{array}{l}1.04 \\
1.21 \\
1.37 \\
1.51 \\
1.67 \\
1.86 \\
2.11\end{array}$ & $\begin{array}{l}1.08 \\
1.24 \\
1.40 \\
1.55 \\
1.75 \\
1.99 \\
2.32\end{array}$ & $\begin{array}{r}\% \\
4 \\
3 \\
2 \\
2 \\
3 \\
4 \\
6 \\
9\end{array}$ & $\begin{array}{l}1.05 \\
1.21 \\
1.39 \\
1.58 \\
1.79 \\
2.04 \\
2.39\end{array}$ & $\begin{array}{l}1.09 \\
1.24 \\
1.40 \\
1.63 \\
1.89 \\
2.14 \\
2.45\end{array}$ & $\begin{array}{l}4 \\
3 \\
1 \\
4 \\
5 \\
5 \\
3\end{array}$ \\
\hline & \multicolumn{2}{|c|}{$\underset{\substack{n=5 \\
v_{m}=24.55}}{\operatorname{Exp}} 21$} & \multicolumn{2}{|c|}{$\begin{array}{c}\text { Exp. } 21 \\
n=5 \\
v_{m}=23.26\end{array}$} & & & & & & \\
\hline
\end{tabular}


Table 3 contains the data for bone chars at liquid oxygen temperature; these data are shown graphically in figure 15 . It may be of interest at this stage to point out the widely different sources of these samples. The new bone chars were obtained from three separate manufacturers. Service char 9 was furnished by the National Sugar Refining Company. It had been used about a month

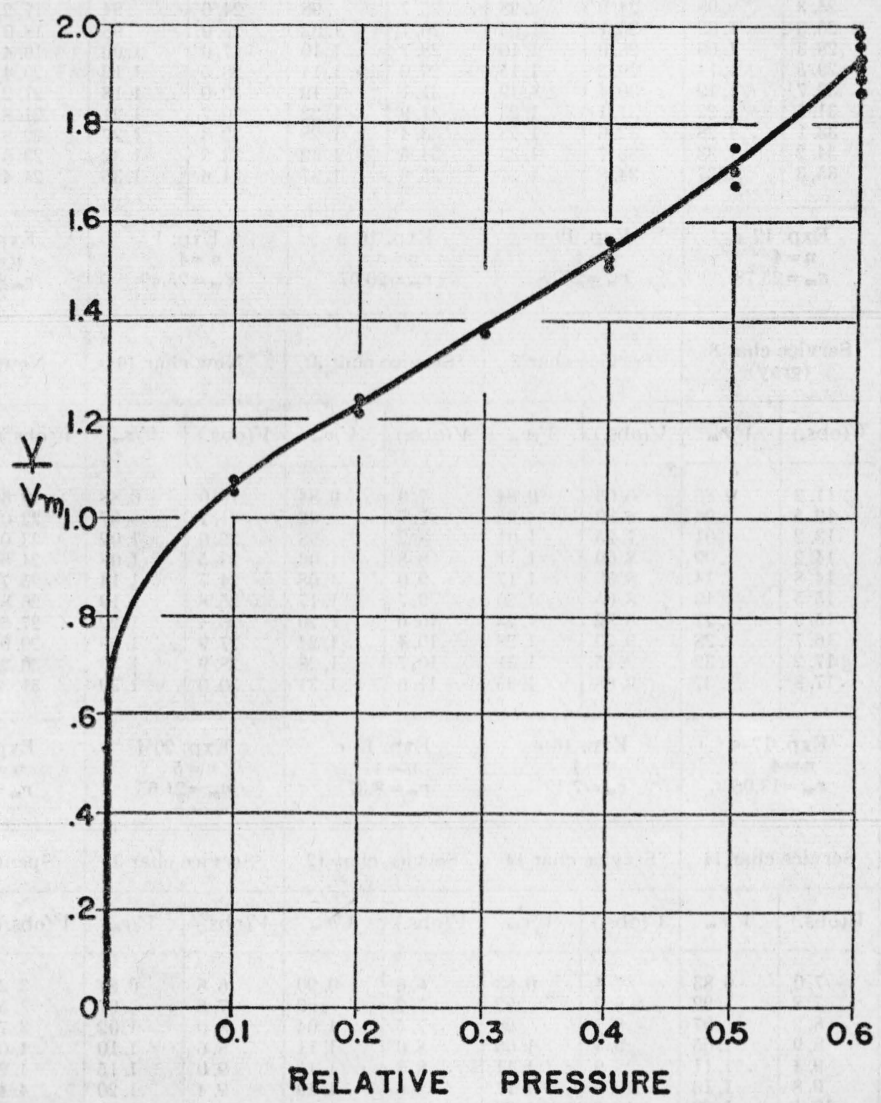

Figure 14.-Adsorption isotherms of nitrogen on eight different bone chars at $77^{\circ} \mathrm{K}$ reduced to unit surface in a plot of $V / v_{m}$ against $p / p_{0}$

For the data see table 2.

and then retained as a standard for laboratory filtration tests. Service char 3 is an example of a bone black in the latter stages of its effectiveness; spent char 15 had been discarded by the Revere Sugar Refinery; service char 14 was obtained from the Savannah Sugar Refinery; service char 8 is a good decolorizer, although the carbon had been reduced in revivification furnaces to 2.7 percent, leaving the material of a gray appearance. An experiment is planned in which a sample of bone char will be subjected to repeated decolorization and revivification cycles and the adsorption of nitrogen per unit surface determined at various stages. Such data will offer a better test for the constancy of the adsorption reduced to unit surface. 


\section{Journal of Research of the National Bureau of Standards}

TABLE 3.-Value of $V / v_{m}$ for the adsorption of nitrogen on bone chars at $90^{\circ} \mathrm{K}$ [Values given under $V$ are in milliliters at STP]

\begin{tabular}{|c|c|c|c|c|c|c|c|c|c|c|}
\hline \multirow{2}{*}{$x$} & \multicolumn{2}{|c|}{ New char 2} & \multicolumn{2}{|c|}{ New char 2} & \multicolumn{2}{|c|}{ New char 2} & \multicolumn{2}{|c|}{ New char 2} & \multicolumn{2}{|c|}{ Service char 9} \\
\hline & $V($ obs. $)$ & $V / v_{m}$ & $V$ (obs.) & $V / v_{m}$ & $V$ (obs.) & $V / v_{m}$ & $V($ obs. $)$ & $V / v_{m}$ & $V$ (obs.) & $V / v_{m}$ \\
\hline \multirow[t]{2}{*}{$\begin{array}{l}0.03 \\
0.06 \\
0.08 \\
0.12 \\
0.15 \\
0.18 \\
0.20 \\
0.24 \\
0.27 \\
0.30\end{array}$} & $\begin{array}{l}22.7 \\
25.3 \\
26.3 \\
28.3 \\
29.5 \\
30.7 \\
31.5 \\
33.1 \\
34.2 \\
35.3\end{array}$ & $\begin{array}{l}0.88 \\
.98 \\
1.02 \\
1.09 \\
1.14 \\
1.19 \\
1.22 \\
1.28 \\
1.33 \\
1.37\end{array}$ & $\begin{array}{l}22.2 \\
24.9 \\
26.1 \\
28.0 \\
29.2 \\
30.4 \\
31.1 \\
32.6 \\
33.7 \\
34.8\end{array}$ & $\begin{array}{l}0.87 \\
.98 \\
1.03 \\
1.10 \\
1.15 \\
1.19 \\
1.23 \\
1.28 \\
1.33 \\
1.37\end{array}$ & $\begin{array}{l}22.8 \\
25.7 \\
26.7 \\
28.7 \\
29.9 \\
31.1 \\
31.9 \\
33.4 \\
34.5 \\
35.6\end{array}$ & $\begin{array}{l}0.87 \\
.98 \\
1.02 \\
1.10 \\
1.14 \\
1.19 \\
1.22 \\
1.28 \\
1.32 \\
1.37\end{array}$ & $\begin{array}{l}22.1 \\
24.0 \\
25.0 \\
27.0 \\
28.5 \\
30.0 \\
30.7 \\
32.3 \\
33.5 \\
34.6\end{array}$ & $\begin{array}{r}0.87 \\
.94 \\
.98 \\
1.06 \\
1.12 \\
1.18 \\
1.21 \\
1.27 \\
1.32 \\
1.36\end{array}$ & $\begin{array}{l}15.2 \\
17.2 \\
18.0 \\
19.4 \\
20.4 \\
21.2 \\
21.8 \\
22.8 \\
23.6 \\
24.4\end{array}$ & $\begin{array}{l}0.85 \\
.96 \\
1.01 \\
1.09 \\
1.14 \\
1.18 \\
1.21 \\
1.27 \\
1.32 \\
1.36\end{array}$ \\
\hline & \multicolumn{2}{|c|}{$\begin{array}{c}\text { Exp. } 12-\mathrm{c} \\
n=4 \\
v_{m}=25.78\end{array}$} & \multicolumn{2}{|c|}{$\begin{array}{c}\text { Exp. } 19-\mathrm{c} \\
\begin{array}{c}n=4 \\
v_{m}=25.38\end{array}\end{array}$} & \multicolumn{2}{|c|}{$\begin{array}{c}\text { Exp. } 16-\mathrm{c} \\
n=4 \\
v_{m}=26.07\end{array}$} & \multicolumn{2}{|c|}{$\begin{array}{c}\text { Exp. } 1 \\
n=4 \\
v_{m}=25.49\end{array}$} & \multicolumn{2}{|c|}{$\begin{array}{c}\text { Exp. } 17-8 \\
n=4 \\
v_{m}=17.97\end{array}$} \\
\hline \multirow{2}{*}{$x$} & \multicolumn{2}{|c|}{$\begin{array}{c}\text { Service char } 8 \\
\text { (gray) }\end{array}$} & \multicolumn{2}{|c|}{ Service char 3} & \multicolumn{2}{|c|}{ Service char 3} & \multicolumn{2}{|c|}{ New char 16} & \multicolumn{2}{|c|}{ New char $C$} \\
\hline & $V($ obs.) & $V / v_{m}$ & $V($ obs.) & $V / v_{m}$ & $V($ obs.) & $V / v_{m}$ & $V($ obs. $)$ & $V / v_{m}$ & $V($ obs.) & $V / v_{m}$ \\
\hline \multirow[t]{4}{*}{$\begin{array}{l}0.03 \\
0.06 \\
0.08 \\
0.12 \\
0.15 \\
0.18 \\
0.20 \\
0.24 \\
0.27 \\
0.30\end{array}$} & $\begin{array}{l}11.2 \\
12.5 \\
13.2 \\
14.2 \\
14.8 \\
15.5 \\
15.9 \\
16.7 \\
17.2 \\
17.8\end{array}$ & $\begin{array}{l}0.86 \\
.96 \\
1.01 \\
1.09 \\
1.14 \\
1.19 \\
1.22 \\
1.28 \\
1.32 \\
1.37\end{array}$ & $\begin{array}{l}6.03 \\
6.80 \\
7.25 \\
8.00 \\
8.38 \\
8.65 \\
8.82 \\
9.20 \\
9.45 \\
9.68\end{array}$ & $\begin{array}{l}0.84 \\
.95 \\
1.01 \\
1.11 \\
1.17 \\
1.20 \\
1.23 \\
1.28 \\
1.31 \\
1.35\end{array}$ & $\begin{array}{r}7.0 \\
7.7 \\
8.2 \\
8.8 \\
9.0 \\
9.7 \\
10.0 \\
10.4 \\
10.7 \\
11.0\end{array}$ & $\begin{array}{r}0.84 \\
.92 \\
.98 \\
1.06 \\
1.08 \\
1.17 \\
1.20 \\
1.24 \\
1.28 \\
1.31\end{array}$ & $\begin{array}{l}19.0 \\
21.1 \\
22.0 \\
23.5 \\
24.7 \\
25.8 \\
26.4 \\
27.9 \\
28.9 \\
30.0\end{array}$ & $\begin{array}{l}0.88 \\
.97 \\
1.02 \\
1.08 \\
1.14 \\
1.19 \\
1.22 \\
1.29 \\
1.33 \\
1.39\end{array}$ & $\begin{array}{l}19.6 \\
22.0 \\
23.0 \\
24.6 \\
25.7 \\
26.8 \\
27.6 \\
29.0 \\
30.2 \\
31.3\end{array}$ & $\begin{array}{r}0.87 \\
.97 \\
1.02 \\
1.09 \\
1.13 \\
1.18 \\
1.22 \\
1.28 \\
1.33 \\
1.38\end{array}$ \\
\hline & \multicolumn{2}{|c|}{$\begin{array}{c}\text { Exp. } 17-a \\
n=4 \\
v_{m}=13.06\end{array}$} & \multicolumn{2}{|c|}{$\begin{array}{c}\text { Exp. } 16-\mathrm{e} \\
n=4 \\
v_{m}=7.19\end{array}$} & \multicolumn{2}{|c|}{$\begin{array}{c}\text { Exp. } 19-\mathrm{c} \\
n=4 \\
v_{m}=8.37\end{array}$} & \multicolumn{2}{|c|}{$\begin{array}{c}\text { Exp. } 20-\mathrm{j} \\
n=5 \\
v_{m}=21.65\end{array}$} & \multicolumn{2}{|c|}{$\begin{array}{c}\text { Exp. } 21-\mathrm{b} \\
n=5 \\
v_{m}=22.64\end{array}$} \\
\hline & \multicolumn{2}{|c|}{ Service char 14} & \multicolumn{2}{|c|}{ Service char 14} & \multicolumn{2}{|c|}{ Service char 12} & \multicolumn{2}{|c|}{ Service char 3} & \multicolumn{2}{|c|}{ Spent char 15} \\
\hline & $V($ obs.) & $V / v_{m}$ & $V($ obs.) & $V / v_{m}$ & $V($ obs.) & $V / v_{m}$ & $V($ obs. $)$ & $V / v_{m}$ & $V$ (obs.) & $V / v_{m}$ \\
\hline \multirow[t]{2}{*}{$\begin{array}{l}0.03 \ldots \ldots \\
0.06 \\
0.08 \\
0.12 \ldots \ldots \\
0.15 \\
0.18 \ldots \ldots \\
0.20 \ldots \ldots \\
0.24 \\
0.27 \\
0.30\end{array}$} & $\begin{array}{r}7.0 \\
7.8 \\
8.2 \\
8.9 \\
9.4 \\
9.8 \\
10.1 \\
10.7 \\
11.0 \\
11.4\end{array}$ & $\begin{array}{r}0.83 \\
.92 \\
.97 \\
1.05 \\
1.11 \\
1.16 \\
1.20 \\
1.26 \\
1.30 \\
1.35\end{array}$ & $\begin{array}{r}7.4 \\
8.2 \\
8.7 \\
9.4 \\
9.9 \\
10.3 \\
10.6 \\
11.2 \\
11.7 \\
12.1\end{array}$ & $\begin{array}{r}0.83 \\
.92 \\
.98 \\
1.06 \\
1.11 \\
1.17 \\
1.20 \\
1.27 \\
1.32 \\
1.37\end{array}$ & $\begin{array}{l}6.6 \\
7.2 \\
7.5 \\
8.0 \\
8.3 \\
8.6 \\
8.8 \\
9.1 \\
9.5 \\
9.7\end{array}$ & $\begin{array}{l}0.90 \\
.99 \\
1.04 \\
1.11 \\
1.15 \\
1.19 \\
1.21 \\
1.25 \\
1.30 \\
1.34\end{array}$ & $\begin{array}{r}6.8 \\
7.6 \\
8.0 \\
8.6 \\
9.0 \\
9.4 \\
9.6 \\
10.2 \\
10.6 \\
11.0\end{array}$ & $\begin{array}{l}0.87 \\
.97 \\
1.02 \\
1.10 \\
1.15 \\
1.20 \\
1.23 \\
1.30 \\
1.35 \\
1.40\end{array}$ & $\begin{array}{l}3.2 \\
3.5 \\
3.7 \\
4.0 \\
4.2 \\
4.4 \\
4.5 \\
4.8 \\
5.0 \\
5.1\end{array}$ & $\begin{array}{r}0.84 \\
.93 \\
.99 \\
1.07 \\
1.12 \\
1.17 \\
1.20 \\
1.26 \\
1.31 \\
1.36\end{array}$ \\
\hline & \multicolumn{2}{|c|}{$\begin{array}{c}\text { Exp. } 8 \\
n=5 \\
v_{m}=8.51\end{array}$} & \multicolumn{2}{|c|}{$\begin{array}{c}\text { Exp. } 10 \\
n=5 \\
v_{m}=8.89\end{array}$} & \multicolumn{2}{|c|}{$\begin{array}{c}\text { Exp. } 1 \\
n=4 \\
v_{m}=7.28\end{array}$} & \multicolumn{2}{|c|}{$\begin{array}{c}\text { Exp. } 12-\mathrm{e} \\
n=4 \\
\theta_{m}=7.85\end{array}$} & \multicolumn{2}{|c|}{$\begin{array}{c}\text { Exp. } 10 \\
n=4 \\
v_{m}=3.82\end{array}$} \\
\hline 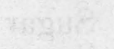 & & & \multicolumn{4}{|c|}{ Spread of $V / v_{m}$ for $n=4$} & Sp & read of I & $V / n_{n}$ for $n$ & $q=5$ \\
\hline & $x$ & & Min. & $\mathrm{M}$ & Max. & Deviation & Min. & & Iax. & Deviation \\
\hline $\begin{array}{l}0.03 \ldots \ldots \\
0.06 \ldots \ldots \\
0.08 \ldots \ldots \\
0.12 \ldots \ldots \\
0.15 \ldots \ldots \\
0.18 \ldots \ldots \\
0.20 \ldots \ldots \\
0.24 \ldots \ldots \\
0.27 \ldots \ldots \\
0.30 \ldots \ldots\end{array}$ & . & . & $\begin{array}{r}0.8 \\
.9 \\
.9 \\
1.0 \\
1.0 \\
1.1 \\
1.2 \\
1.2 \\
1.2 \\
1.3\end{array}$ & $\begin{array}{l}84 \\
92 \\
98 \\
06 \\
08 \\
17 \\
20 \\
24 \\
28 \\
31\end{array}$ & $\begin{array}{r}0.90 \\
.99 \\
1.03 \\
1.11 \\
1.17 \\
1.20 \\
1.23 \\
1.30 \\
1.35 \\
1.40\end{array}$ & $\begin{array}{l}6 \\
7 \\
5 \\
5 \\
8 \\
3 \\
3 \\
5 \\
5 \\
5\end{array}$ & $\begin{array}{r}0.8 \\
.9 \\
.9 \\
1.0 \\
1.1 \\
1.1 \\
1.2 \\
1.2 \\
1.3 \\
1.3\end{array}$ & $\begin{array}{l}83 \\
92 \\
97 \\
95 \\
11 \\
16 \\
20 \\
26 \\
30 \\
35\end{array}$ & $\begin{array}{l}0.88 \\
.97 \\
1.02 \\
1.09 \\
1.14 \\
1.19 \\
1.22 \\
1.29 \\
1.33 \\
1.39\end{array}$ & $\begin{array}{l}6 \\
6 \\
5 \\
4 \\
3 \\
2 \\
2 \\
3 \\
3 \\
3\end{array}$ \\
\hline
\end{tabular}




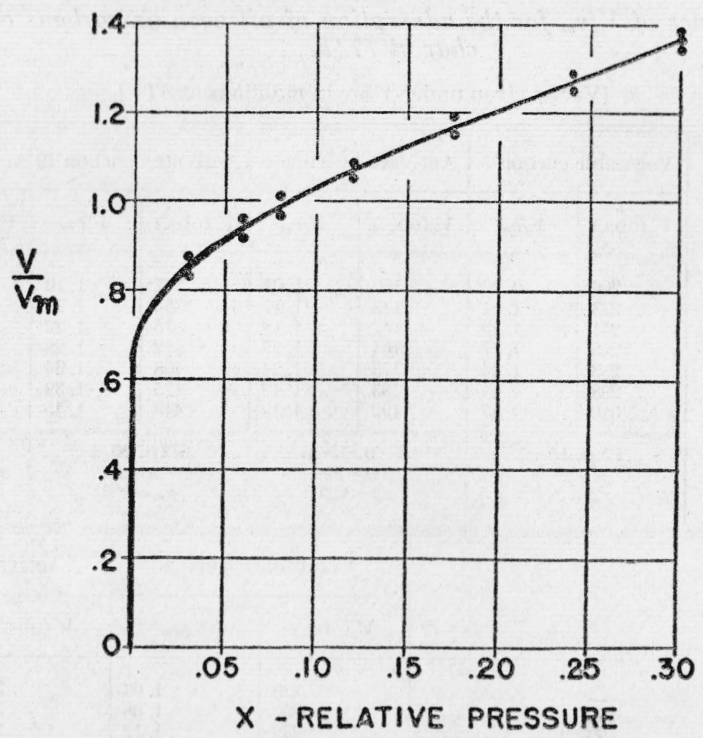

FIGURE 15.-Adsorption isotherms of nitrogen on eight different bone chars at $90^{\circ} \mathrm{K}$ reduced to unit surface in a plot of $V / v_{m}$ against $p / p_{0}$.

For the data see table 3 .

A possible interpretation of these results is to be found in attributing approximately the same pore-size distribution to all the bone char samples investigated. Moreover in these adsorption measurements the fraction of surface covered varies between $0.8 v_{m}$ to $2 v_{m}$. Consequently, the determinations are being made on the most uniform portion of the surface, since the active or other heterogeneous regions have already been covered in the early stages. In this manner a pure surface effect is measured which is independent of chemisorptive influences.

The results for the samples other than bone black show analogous behavior but with significant differences for the value of $n$. Tables 4 and 5 are obtained from the data on such samples. The isotherms for the chars with the value of $n=2$ fall into a group about a single reduced isotherm; similarly, the two carbons with $n=1.5$ constitute another group. If one considers the data for all the adsorbents, including the coconut-shell charcoals, five curves are characterized by $n=1,1.5,2,4$, or 5 , and these suffice to plot the nitrogen adsorption per unit surface. These reduced isotherms are illustrated in figures 16 and 17. The conclusion may be drawn that the value of $n$ is a quantitative index, of limited accuracy, of the maximum average diameter of those pores effective in adsorption at relative pressures less than 0.6 . 


\section{Journal of Research of the National Bureau of Standards}

TABLE 4.-Values of $V / v_{m}$ for the adsorption of nitrogen on carbons other than bone char at $77^{\circ} \mathrm{K}$

[Values given under $V$ are in milliliters at STP]

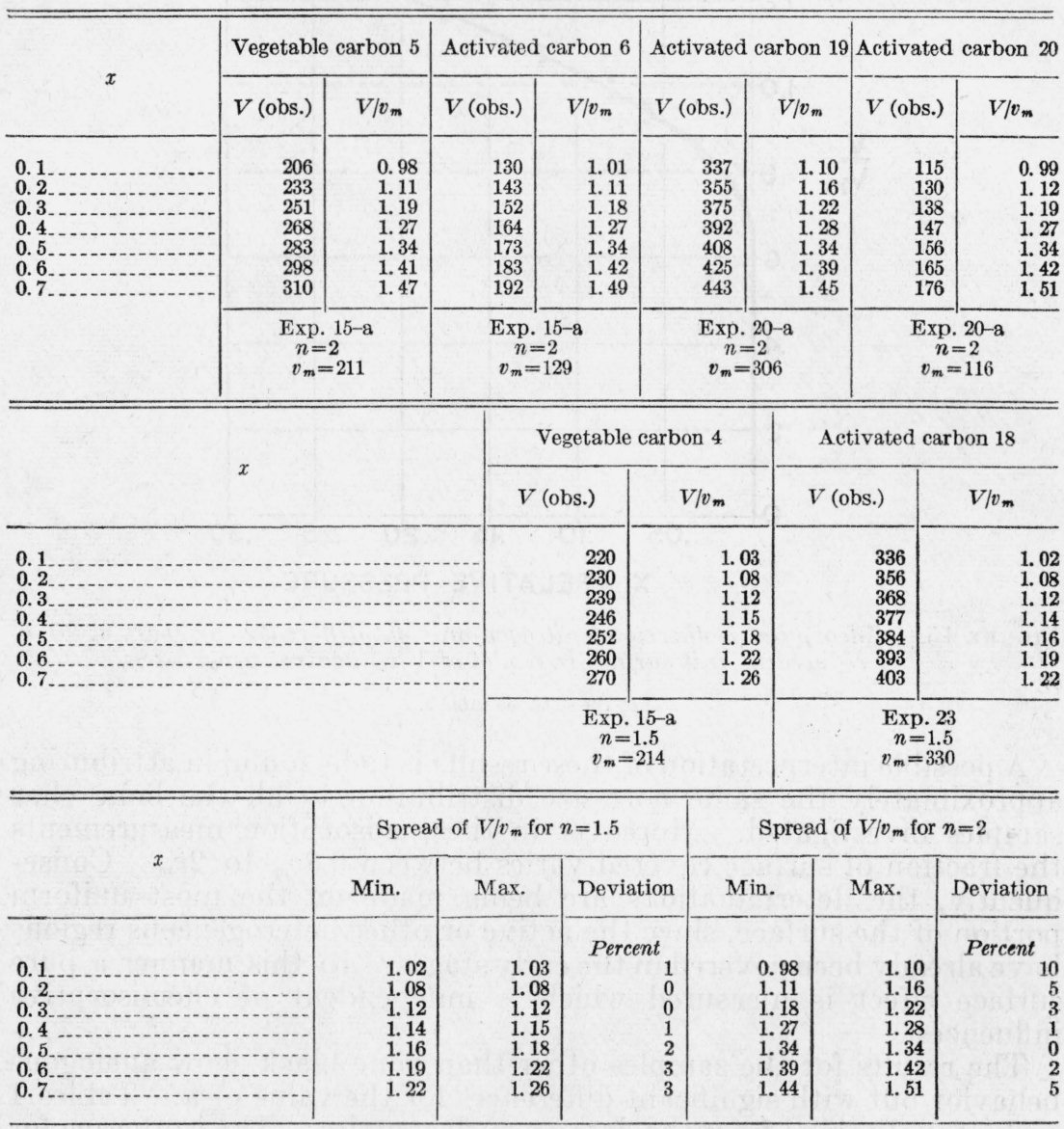


TABLE 5.-Values of $V / v_{m}$ for the adsorption of nitrogen on carbons other than bone char at $90^{\circ} \mathrm{K}$

[Values given under $V$ are in milliliters at STP]

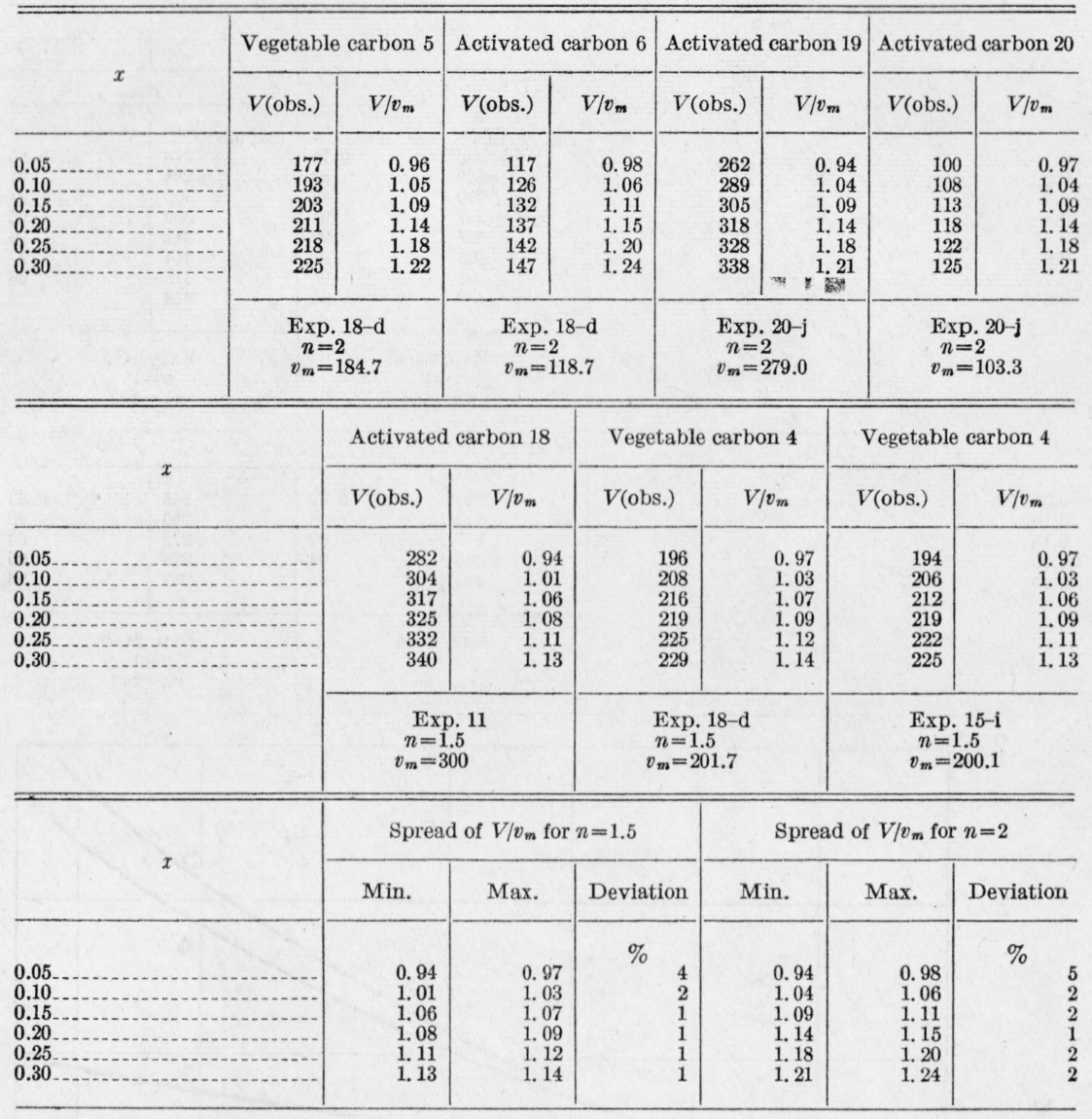


218 Journat of Research of the National Bureau of Standards

TABLE"6.-Value of $V i v_{m}$ for the adsorption of nitrogen on coconut charcoal

\begin{tabular}{|c|c|c|c|c|c|}
\hline \multirow{2}{*}{$x$} & \multicolumn{2}{|c|}{ Charcoal 1} & \multicolumn{3}{|c|}{ Charcoal 17} \\
\hline & $V$ & $V / v_{m}$ & $V$ & & \\
\hline \multicolumn{6}{|c|}{ at $77^{\circ} \mathrm{K}$} \\
\hline \multirow[t]{2}{*}{$\begin{array}{l}0.1 \\
0.2 \\
0.3 \\
0.4 \\
0.6 \\
0.6\end{array}$} & $\begin{array}{r}m l \text { at STP } \\
306 \\
359 \\
380 \\
391 \\
397 \\
403 \\
407 \\
409\end{array}$ & $\begin{array}{r}0.71 \\
.84 \\
.88 \\
.91 \\
.92 \\
.94 \\
.95 \\
.95\end{array}$ & $\begin{array}{r}\text { ml at STP } \\
276 \\
294 \\
305 \\
309 \\
312 \\
314 \\
316 \\
318\end{array}$ & & $\begin{array}{l}0.85 \\
.91 \\
.94 \\
.95 \\
.96 \\
.97 \\
.98 \\
.99\end{array}$ \\
\hline & \multicolumn{2}{|c|}{$\begin{array}{c}\text { Exp. } 14-9 \\
n=1 \\
v_{m}=430\end{array}$} & \multicolumn{3}{|c|}{$\begin{array}{c}\text { Exp. } 24 \text { e } \\
n=1 \\
v_{m}=323\end{array}$} \\
\hline \multicolumn{6}{|c|}{ at $90^{\circ} \mathrm{K}$} \\
\hline \multirow[t]{2}{*}{$\begin{array}{l}0.05 \\
0.10 \\
0.15 \\
0.20 \\
0.25\end{array}$} & $\begin{array}{l}289 \\
322 \\
377 \\
345 \\
350\end{array}$ & $\begin{array}{r}0.79 \\
.88 \\
.92 \\
.94 \\
.95\end{array}$ & $\begin{array}{l}245 \\
266 \\
275 \\
279 \\
282\end{array}$ & & $\begin{array}{r}0.83 \\
.90 \\
.93 \\
.95 \\
.96\end{array}$ \\
\hline & \multicolumn{2}{|c|}{$\begin{array}{c}\text { Exp. } 16-a \\
n=1 \\
v_{m}=367\end{array}$} & \multicolumn{3}{|c|}{$\begin{array}{c}\text { Exp. 24-b } \\
n=1 \\
v_{m}=293\end{array}$} \\
\hline
\end{tabular}

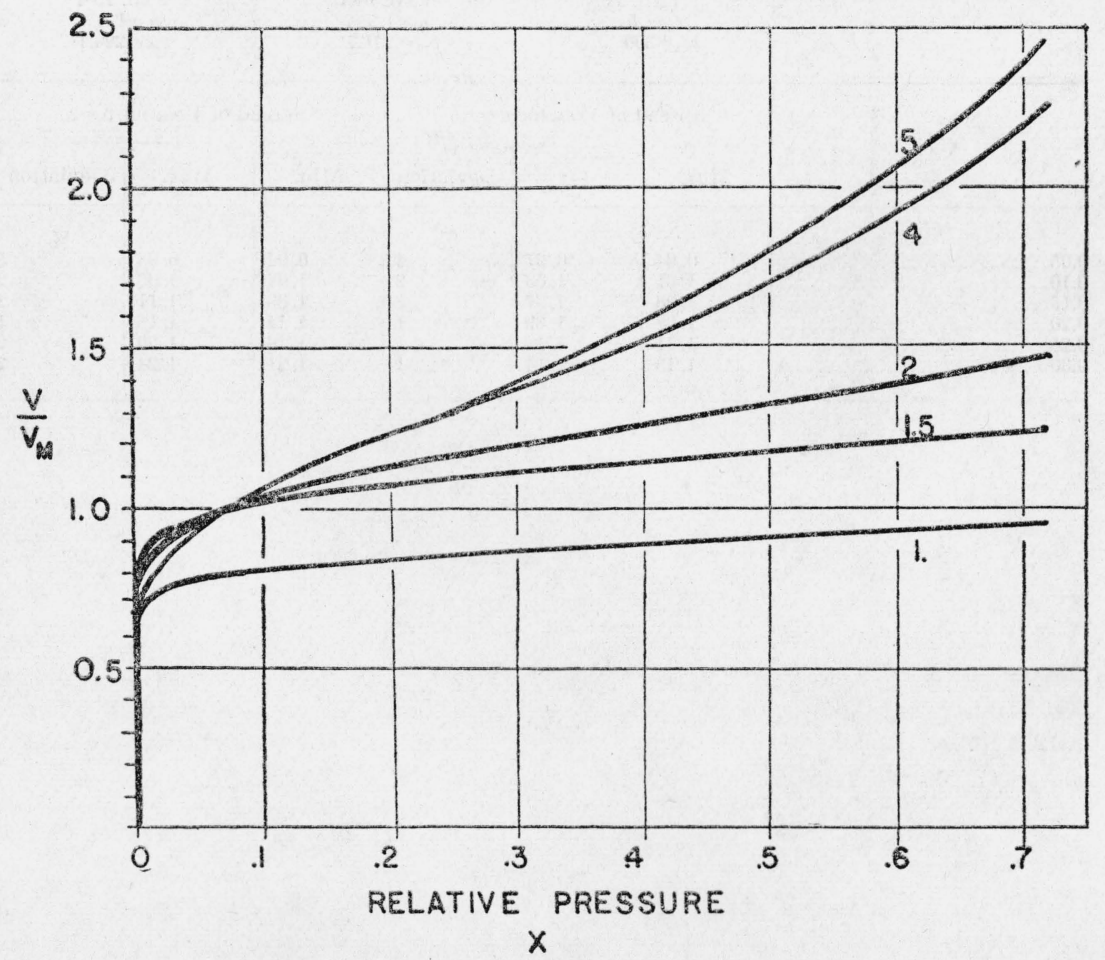

FIGURE 16.-Adsorption isotherms of nitrogen at $77^{\circ} \mathrm{K}$ reduced to unit surface for the five classes of adsorbents characterized by $n=1,1.5,2,4$, and 5 .

For the data, see tables 2, 4 , and 6 . 


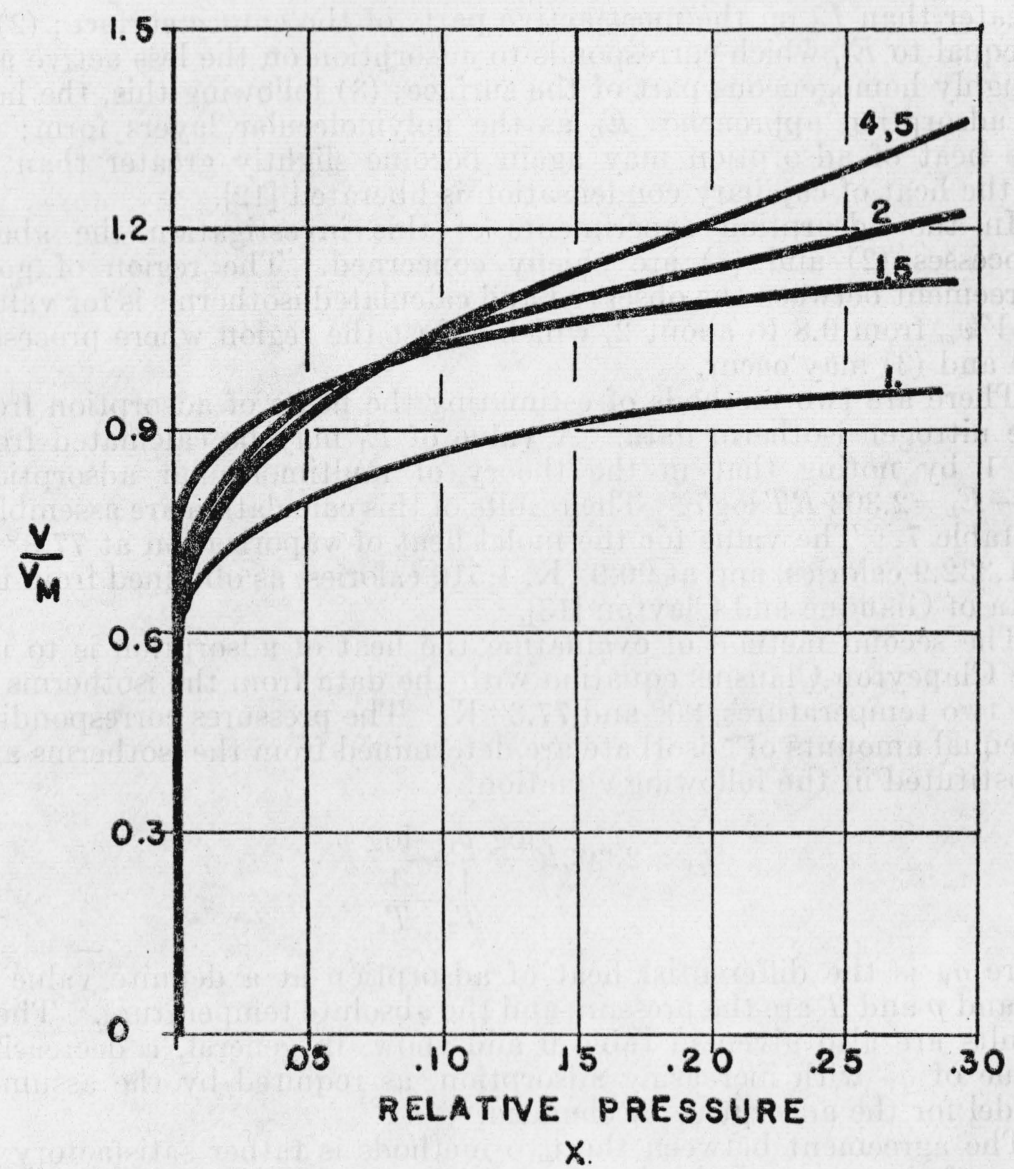

FIGURE 17.-Adsorption isotherms of nitrogen at $90^{\circ} \mathrm{K}$ reduced to unit surface for the five classes of adsorbents characterized by $n=1,1.5,2,4$, and 5 .

For the data see tables 3,5 , and 6 .

The question may arise as to whether the method of determining $v_{m}$ would necessarily lead to identical values of $V / v_{m}$ at a given value of $x$ for all the bone chars. However, from eq 1 it is seen that $V / v_{m}$ at a given value of $x$ is a function of $n$, and thus for a given value of $n$, $V / v_{m}$ depends only on $c$. But from the nature of van der Waals' forces of adsorption, $c$ is substantially constant for the same type of materials in this pressure range. Therefore the equivalence of the adsorption per unit surface is verification of a similar distribution of pore sizes in all those samples in which $n$ is the same.

\section{HEATS OF ADSORPTION}

As the process of adsorption progresses from the earliest stages to saturation, the heat of adsorption may change somewhat as follows: (1) Designating $E_{L}$ as the heat of liquefaction and $E_{1}$ as the average heat of adsorption on the first layer, the heat of adsorption may be 
greater than $E_{1}$ on the most active parts of the empty surface; (2) it is equal to $E_{1}$, which corresponds to adsorption on the less active and roughly homogeneous part of the surface; (3) following this, the heat of adsorption approaches $E_{L}$ as the polymolecular layers form; (4) the heat of adsorption may again become slightly greater than $E_{L}$ as the heat of capillary condensation is liberated [12].

In the adsorption experiments of this investigation the above processes (2) and (3) are chiefly concerned. The region of good agreement between the observed and calculated isotherms is for values of $V / v_{m}$ from 0.8 to about 2 , which is just the region where processes (2) and (3) may occur.

There are two methods of estimating the heats of adsorption from the nitrogen isotherm data. A value of $E_{1}$ may be calculated from eq 1 by noting that in the theory of multimolecular adsorption, $E_{1}-E_{L}=2.303 R T \log c$. The results of this calculation are assembled in table 7. The value for the molal heat of vaporization at $77.3^{\circ} \mathrm{K}$ is $1,332.9$ calories, and at $90.0^{\circ} \mathrm{K}, 1,510$ calories, as obtained from the data of Giauque and Clayton [13].

The second method of evaluating the heat of adsorption is to use the Clapeyron-Clausius equation with the data from the isotherms at the two temperatures, $90^{\circ}$ and $77.3^{\circ} \mathrm{K}$. The pressures corresponding to equal amounts of adsorbate are determined from the isotherms and substituted in the following equation:

$$
q_{V}=2.303 R \frac{\log p_{1}-\log p_{2}}{\frac{1}{T_{2}}-\frac{1}{T_{1}}}
$$

Here $q_{V}$ is the differential heat of adsorption at a definite value of $V$, and $p$ and $T$ are the pressure and the absolute temperature. These results are also given in table 6 and show, in general, a decreasing value of $q_{v}$ with increasing adsorption, as required by the assumed model for the adsorptive mechanism.

The agreement between the two methods is rather satisfactory in view of the uncertainties involved. The same amount of adsorbate at two different temperatures may not be in strictly comparable conditions. Something comparable to this situation must exist for the adsorbents of high surface having a value of $n=1,1.5$, and 2 , since the surface determined at the lower temperature is appreciably greater. It is to be noted in table 6 that the value for $q_{V}$ decreases toward $E_{L}$ as the volume adsorbed increases.

Table 7 contains the calculated $E_{1}$ values from each isotherm at the two temperatures. The difference between the two, $\Delta E_{1}$, is on the average greater than the difference between the heats of vaporization, namely $E_{L}\left(90^{\circ}\right)-E_{L}\left(77.3^{\circ}\right)=1,510-1,335=175$ calories.

TABLE 7.-Comparison of $E_{1}$ with the calculated differential heats of adsorption

\begin{tabular}{|c|c|c|c|c|c|}
\hline Sample & $T$ & $E_{1}-E_{\mathrm{L}}$ & $E_{1}$ & $\Delta E_{1}$ & $\begin{array}{l}\text { Differential heats } \\
\text { of adsorption } \\
\text { (in calories) }\end{array}$ \\
\hline & ${ }^{\circ} K$ & Calories & Calories & Calories & $(g(V-25)-2145$ \\
\hline 2 & $\begin{array}{l}76.4 \\
89.7\end{array}$ & $\begin{array}{l}890 \\
945\end{array}$ & $\begin{array}{l}2,230 \\
2,470\end{array}$ & $\quad 240$ & $\left\{\begin{array}{l}q(V=25)=2,145 \\
q(V=30)=1,760 \\
q(V=35)=1,620\end{array}\right.$ \\
\hline$C$ & $\begin{array}{l}77.3 \\
90.1\end{array}$ & $\begin{array}{l}850 \\
910\end{array}$ & $\begin{array}{l}2,180 \\
2,420\end{array}$ & 240 & $\left\{\begin{array}{l}q(V=25)=1,920 \\
q(V=30)=1,660\end{array}\right.$ \\
\hline
\end{tabular}


TABLE 7.-Comparison of $E_{1}$ with the calculated differential heats of adsorption-Continued

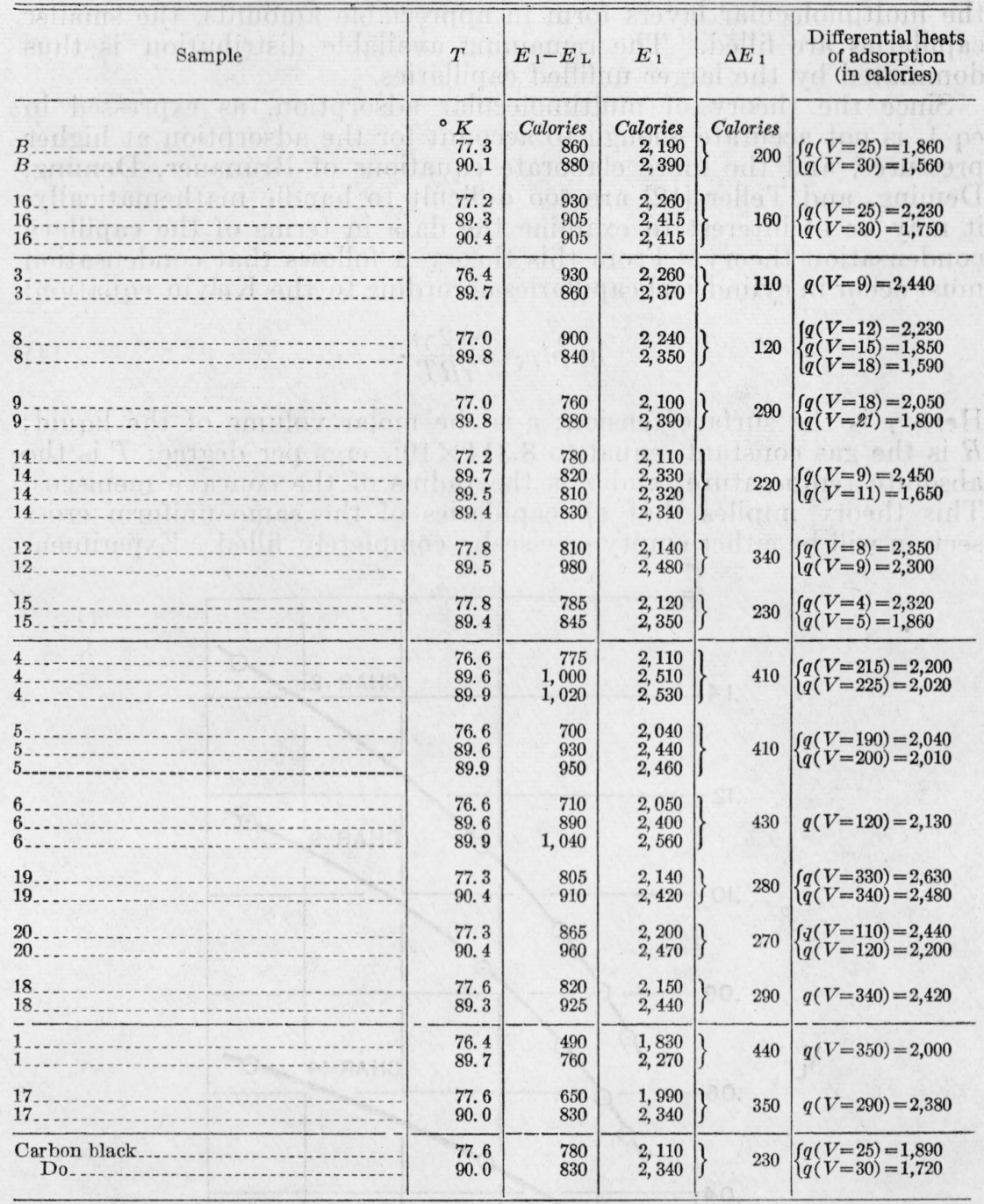

\section{DEPENDENCE OF THE ADSORPTION ON CAPILLARITY}

It has been shown that the nitrogen isotherms obtained in these experiments may be interpreted by means of the multimolecular adsorption theory of Brunauer, Emmett, and Teller for values of $x$ from 0.1 to 0.5 for bone-char samples as well as for vegetable carbons. In this theory the concept of capillarity enters through the restriction of multimolecular adsorption caused by the proximity of plane parallel walls between which the adsorption takes place. The region of adsorption between $x=0.5$ and saturation might most probably be 
interpreted, at least from a qualitative point of view, in terms of a change in pore-size distribution. As the adsorption progresses and the multimolecular layers form in appreciable amounts, the smaller capillaries are filled. The remaining available distribution is thus dominated by the larger unfilled capillaries.

Since the theory of multimolecular adsorption, as expressed in eq 1 , is not accurate enough to account for the adsorption at higher pressures, and the more elaborate equations of Brunauer, Deming, Deming, and Teller [12] are too difficult to handle mathematically, it may be of interest to examine the data in terms of the capillary condensation theory. From this theory it follows that condensation must occur in cylindrical capillaries according to the Kelvin equation:

$$
\ln p / p_{0}=\frac{-2 \gamma v}{r R T} \text {. }
$$

Here $\gamma$ is the surface tension; $v$ is the molar volume of the liquid; $R$ is the gas constant, equal to $8.314 \times 10^{7}$ ergs per degree; $T$ is the absolute temperature; and $r$ is the radius of the concave meniscus. This theory impiles that all capillaries of the same uniform cross section will be either empty or else be completely filled. Experimen-

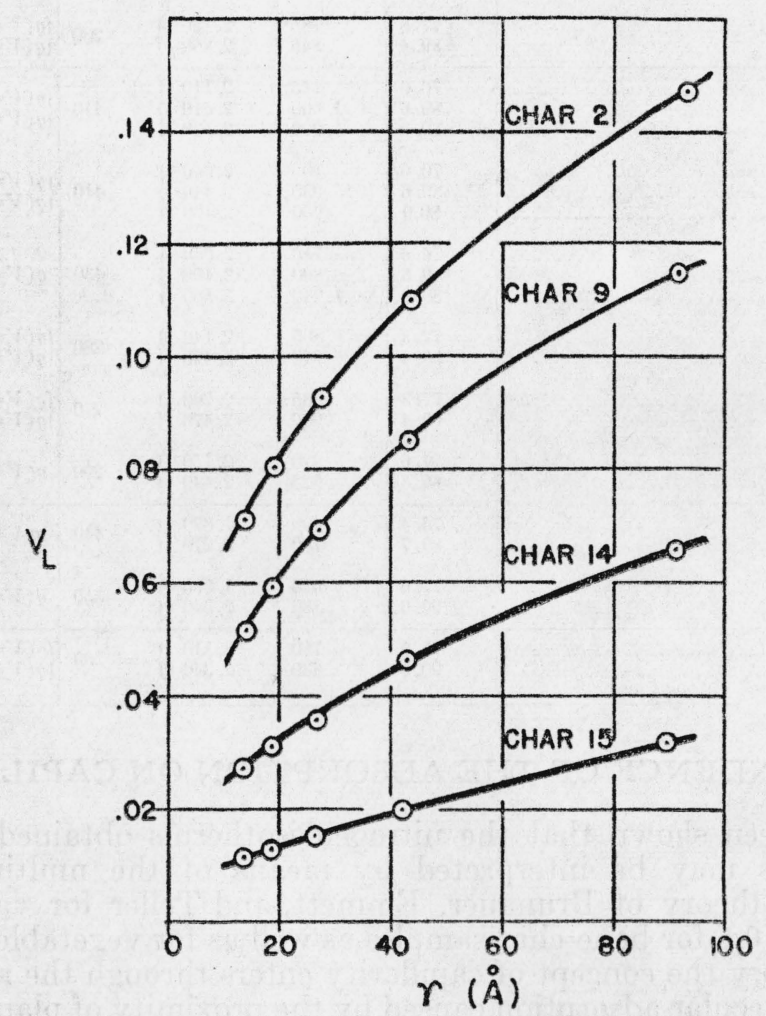

Figure 18.-Adsorption at $77^{\circ} K$ on bone chars in a plot of the volume of liquid nitrogen adsorbed, $V_{L}$, per gram of adsorbent against the corresponding radius of a cylindrical capillary as determined from the Kelvin equation.

The five points in circles correspond to $x=0.5,0,6,0.7,0.8,0.9$, respectively. 


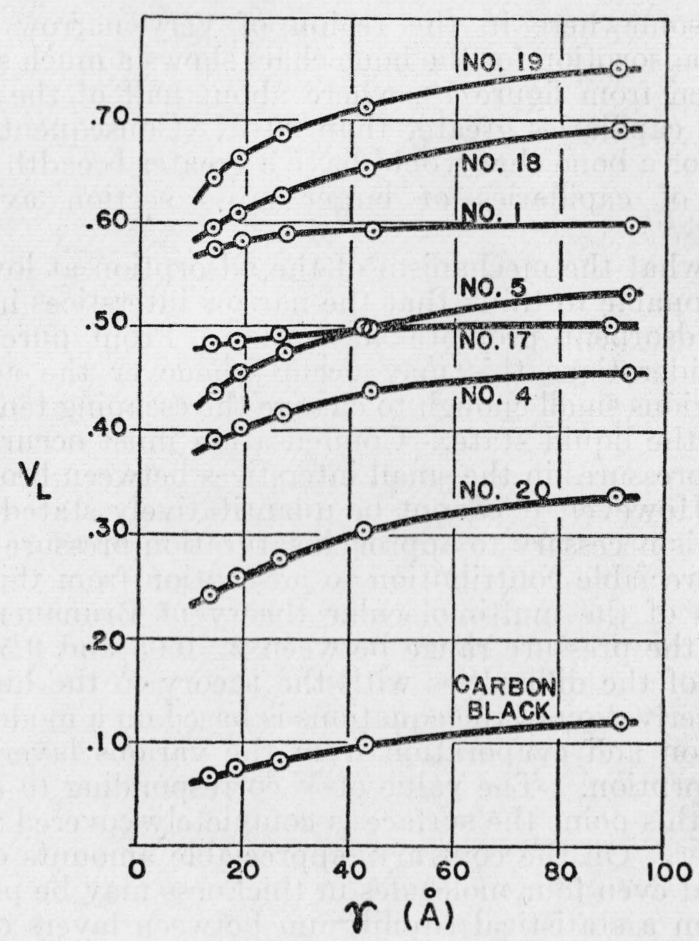

Figure 19.-Adsorption at $77^{\circ} K$ on adsorbent carbons other than bone char in $a$ plot of the volume of liquid nitrogen, $V_{L}$, per gram of adsorbent against the corresponding radius of a cylindrical capillary as determined from the Kelvin equation.

The five points in circles correspond to $x=0.5,0.6,0.7,0.8$, and 0.9 , respectively.

tally the sharp rise in adsorption demanded by the theory has never been found. This has been explained by assuming a continuously varying distribution of the cross sections of the capillaries.

From eq 4 a value of $2 r$ equal to $30 \mathrm{~A}$ is obtained for nitrogen at $77^{\circ} \mathrm{K}$ to correspond to the value of $p / p_{0}$ equal to 0.5 . Since the diameter of the nitrogen molecule considered as a sphere in the liquid state is $4.3 \mathrm{~A}$, a diameter of $30 \mathrm{~A}$ is of plausible order of magnitude for capillary condensation phenomena. In figures 18 and 19 the volume of liquid adsorbed, $V_{L}$, is plotted against $r$ for a number of materials included in this paper. To express the adsorption in milliliters of liquid nitrogen, the density of nitrogen gas at $0^{\circ}$ and $760 \mathrm{~mm}$ was taken to be $1.2506 \mathrm{~g}$ per liter [13]. Equation 4 was used to calculate $r$ from the data of the experiment along with the required constants in the International Critical Tables.

It can be seen from the graphs of $V_{L}$ against $r$ in figure 19 that the slopes of the curves for carbons other than bone char seem to be approaching zero as the adsorption increases. According to the theory of capillary condensation, this would mean that there are only a relatively small number of pores with large radii. The major part of the adsorption on the carbons other than bone chars appears to occur in capillaries of less than 20 A radius. A distribution curve for the capillaries would, therefore, have a relatively narrow breadth and 
a maximum somewhere in the region of very narrow capillaries. However, the adsorption for the bone chars shows a much steeper rise, as may be seen from figure 18, where about half of the adsorption takes place in capillaries greater than $20 \mathrm{~A}$. Consequently a distribution curve for a bone char would have a greater breadth to indicate the presence of capillaries of larger cross section available for adsorption.

No matter what the mechanism of the adsorption at low values of $p / p_{0}$, it is reasonable to think that the narrow interstices in the structure of the adsorbent promote adsorption. From purely thermodynamic considerations this may occur whenever the adsorbate is confined to regions small enough to change the escaping tendency from the value for the liquid state. Condensation must occur, therefore, at the higher pressures in the small interstices between broken crystal aggregates. However, it cannot be quantitatively stated at present how closely it is necessary to approach saturation pressure in order to obtain an appreciable contribution to adsorption from this source.

The success of the multimolecular theory of Brunauer, Emmett, and Teller in the pressure range between $x=0.05$ and 0.5 leads to a consideration of the difficulties with the theory in the high-pressure range. The derivation of the equations is based on a model involving condensation. on and evaporation from the various layers in multimolecular adsorption. The value of $V$ corresponding to $v_{m}$ does not mean that at this point the surface is completely covered with a unimolecular layer. On the contrary, appreciable amounts of layers of two, three, and even four molecules in thickness may be present. In this mechanism a statistical equilibrium between layers of adsorbed molecules is postulated. A complete statistical theory involving the evaporation and condensation of individual molecules would take into account the interaction of neighbors within the layer and thus approach more closely to the actual situation at the higher relative pressures.

One of the main achievements of the theory of multimolecular adsorption as embodied in the papers of Brunauer, Emmett, and Teller [6] and Brunauer, Deming, Deming, and Teller [12] is that it gives a complete picture of van der Waals' adsorption, and accounts for the variety of different-shaped isotherms that can be found in the literature. Although there are difficulties with a quantitative application of the theory close to saturation pressures, it accounts quantitatively for all of the isotherms given in this paper up to about $p / p_{0}=0.6$. For the purpose of this investigation the most important feature is that it enables one to calculate relative values for the specific surfaces of adsorbents with a fair degree of accuracy.

We express our appreciation to Stephen Brunauer, of the Bureau of Plant Industry, United States Department of Agriculture, and to P. H. Emmett, of the John Hopkins University, for valuable discussions on the principles of adsorption involved in this paper. We also express our appreciation to Eloise A. Swick for her assistance in the calculations. 


\section{REFERENCES}

[1] F. Paneth, Z. Elektrochem. 28, 113 (1922).

[2] P. C. Carman, J. Soc. Chem. Ind. 58, 1 (1939).

[3] S. S. Kistler, J. Phys. Chem. 46, 19 (1942).

[4] P. H. Emmett and S. Brunauer, J. Am. Chem. Soc. 59, 1553 (1937).

[5] S. Brunauer and P. H. Emmett, J. Am. Chem. Soc. 59, 2682 (1937).

[6] S. Brunauer, P. H. Emmett, and E. Teller, J. Am. Chem. Soc. 60, 309 (1938)

[7] P. H. Emmett and T. De Witt, Ind. Eng. Chem., Anal. Ed. 13, 28 (1941).

[8] W. R. Smith, F. S. Thornhill, and R. I. Bray, Ind. Eng. Chem. 33, 1303 (1941).

[9] C. T. Lane and W. W. Watson, Rev. Sci. Instr. 11, 272 (1940)

[10] V. R. Deitz and L. F. Gleysteen, J. Research NBS 28, 795-805 (1942) RP 1479 .

[11] I. Langmuir, J. Am. Chem. Soc. 37, 1139 (1915).

[12] S. Brunauer, L. S. Deming, W. E. Deming, and E. Teller, J. Am. Chem. Soc. 62, $1723(1940)$.

[13] W. F. Giauque and J. O. Clayton, J. Am. Chem. Soc. 55, 4881 (1933).

[14] P. H. Emmett, Am. Soc. Testing Materials, Symposium on New Methods for Particle Size Determination in Subsieve Range, 41, 95-106 (1941).

Washington, June 26, 1942. 